\title{
Relación entre las facies marinas del Aptiano-Albiano en Chihuahua y Sonora, México
}

\author{
Jorge Alberto Santiago-Bautista, Rogelio Monreal, José F. Longoria, Kinardo Flores-Castro
}

Jorge Alberto Santiago-Bautista

Maestría en Ciencias-Geología, Universidad de Sonora, Blvd. Luis Encinas y Rosales, 83000, Hermosillo, Sonora, México.

\section{Rogelio Monreal}

monreal@ciencias.uson.mx

Departamento de Geología, Universidad de Sonora, Blvd. Luis Encinas y Rosales, 83000, Hermosillo, Sonora, México.

\section{José F. Longoria}

Earth and Environment Department, Florida International University. Miami Florida 33199

\section{Kinardo Flores-Castro}

Laboratorio de Geoquímica, Centro de Investigaciones en Ciencias de la Tierra y Materiales. Universidad Autónoma del Estado de Hidalgo. Mineral de la Reforma, Hidalgo, 42184

BOL. SOC. GEOL. MEX. 2019

VOL. 71 NO. 3

P. $657-689$

http://dx.doi.org/10.18268/BSGM2018v7 ln3a4

Manuscrito recibido: Enero 16, 2018. Manuscrito corregido: Abril 2, 2018. Manuscrito aceptado: Mayo 20, 2018.

\section{RESUMEN}

Las secciones estudiadas en la Sierra Banco de Lucero en Chihuahua y La Sierra Las Azules en Sonora, están formadas predominantemente por calizas micríticas y calizas arenosas, con algunas intercalaciones de lutitas calcáreas. Ambas secciones contienen asociaciones faunísticas muy similares. En ambas localidades se observan variaciones ambientales como respuesta a cambios del nivel del mar, por lo que la conexión respecto de la continuidad lateral entre ambas secuencias es todavía un poco incierta, estas variantes se reflejan en las microfacies y en menor grado en la diversidad taxonómica de microfósiles planctónicos. De acuerdo al análisis de microfacies, los ambientes dominantes en ambas secciones son de mar abierto pelágico, talud y cuenca, solo en la parte alta de la localidad ubicada en Chihuahua, se reconocieron ambientes de aguas someras que corresponden a la plataforma interior y lagunar. En contraste, la sección Sierra Las Azules, en Sonora, representa condiciones de depósito en aguas más profundas con respecto a la Sierra Banco de Lucero en Chihuahua. Ambas localidades representan el intervalo Aptiano superior-Albiano inferior, sin embargo, son ligeramente diacrónicas, es decir, que posiblemente la sección en Sonora es un poco más antigua que la sección de la Sierra Banco de Lucero. De acuerdo con los datos obtenidos, se confirma la afinidad tanto litoestratigráfica como cronoestratigráfica entre las dos secuencias.

Palabras clave: Gretácico, Microfacies, Sonora, Chihuahua.

\section{ABSTRACT}

The sections studied in the Sierra Banco de Lucero in Chihuahua and Sierra Las Azules in Sonora, are mainly made of micritic limestone and sandy limestone, with some intervals of interbedded shales. Both sections have very similar faunal associations. Both sections display some environmental differences resulting from fluctuation of the sea level, the direct lateral continuity of the two successions remains unresolved, these variations are reflected in the microfacies and also in minor differences in taxonomic diversity of microfossils. The microfacies showes that, the dominant environments in both sections range from pelagic open ocean, to slope and to basin, upper platform and lagoonal environments were identified only in the upper part of the Chihuahua succession. However, the Sierra Las Azules succession, represents deeper conditions with respect to the Banco de Lucero section. Both successions represent the interval comprised between the upper Aptian and the lower Albian, however, they are slightly diacronous; it is likely that the section in Sonora is slightly older than the Banco de Lucero section. Our field and lab data demonstrate the lithostratigraphic and chonostratigraphic affinities between both successions.

Keywords: Cretaceous, Microfacies, Sonora, Chihuahua 


\section{Introducción}

Rocas sedimentarias marinas están ampliamente expuestas en México con abundantes micro y macro fosiles, siendo común encontrar moluscos (cefalópodos, bivalvos y gasterópodos), cnidarios, esponjas y equinodermos, así como diversos grupos de microfósiles como foraminíferos, calpionélidos y ostrácodos (Cantú-Chapa, 1976; Gamper, 1977; Longoria, 1977; Araujo-Mendieta, 1978; González-Arreola y Carrillo-Martínez, 1986; Villaseñor-Martínez y González-Arreola, 1988; Adatte et al., 1994; Ángeles-Villeda, 2004).

En México es común encontrar secuencias cretácicas marinas en las que los foraminíferos planctónicos son abundantes, pudiéndose realizar muestreos continuos; por otra parte, la macrofauna de amonites es escasa dificultando así la determinación cronoestratigráfica y paleoambiental de esas secuencias a nivel de estrato (Longoria, 1977), por lo que deben de utilizarse otros grupos de organismos y otras técnicas para llevar a cabo estudios estratigráficos, paleontológicos y de interpretación paleoambiental.

La utilidad de los microfósiles en estudios tanto estratigráficos como plaeogeográficos y ambientales ha quedado bien fundamentada con los estudios de Bonet (1956); Longoria (1977, 1984), Gamper (1977); Trejo (1980), Longoria y Monreal (1991), entre otros, los cuales han puesto en evidencia que los organismos identificados en una localidad pueden ser comparados con aquellos localizados en otro sitio para ampliar la continuidad geológica, interpretaciones paleoambientales o para hacer las interpretaciones paleogeográficas; de esta manera, el área con rocas cretácicas marinas del noreste del estado de Chihuahua ha sido considerada como perteneciente y de origen similar a localidades ubicadas en la Sierra Madre Oriental (Cordillera Mesozoica Mexicana), por lo que dicha área fue trasladada a su actual localización durante la orogenia Laramide, ocurrida a principios del Terciario. De la misma forma, se han realizado algunos estudios, por ejemplo, Monreal y Longoria (2000) y Monreal (2009), en los cuales se postula que las rocas cretácicas expuestas en el centro-este de Sonora (Lampazos) se relacionan paleogeograficamente con rocas contemporáneas del este de Chihuahua, y que anteriormente habían sido erróneamente adjudicadas por algunos autores como una continuidad del Cretácico del sur de Arizona.

Por lo anterior, el presente trabajo se realizó con la finalidad de obtener datos de campo y laboratorio (microfacies y estudio de microfósiles) que permitan corroborar si la Sierra Las Azules, ubicada en la parte centro-este de Sonora, esta paleogeograficamente relacionada a la Sierra Banco de Lucero, ubicada al norte de Chihuahua, y esta a su vez si ambas se pueden relacionar con diversas localidades del noreste de México tales como el sur de Coahuila, norte de Zacatecas, centro este de Nuevo León y norte de Tamaulipas, la cuales contienen rocas marinas del Aptiano-Albiano.

El presente trabajo trata con la litoestratigrafia, biocronología, microfacies y contenido de foraminíferos planctónicos de la sucesión estratigráfica expuesta en la Sierra Banco de Lucero al norte de Chihuahua y la Sierra Las Azules, centro este de Sonora, para identificar los ambientes sedimentarios de ambas localidades que permitan establecer la afinidad paleogeográfica de la sucesión cretácica de esas regiones del norte de México.

\section{2. Áreas de estudio}

Este estudio se llevó a cabo en dos localidades, la Sierra Banco de Lucero en Chihuahua, y la Sierra Las Azules en el área de Lampazos, Sonora separadas por una distancia recta de $300 \mathrm{~km}$, cuya localización y vías de acceso se describen a continuación:

\subsection{SIERRA BANGO DE LUGERO, GHIHUAHUA}

La Sierra Banco de Lucero se localiza en el municipio de Miguel Ahumada, a $240 \mathrm{~km}$ al noroeste de la ciudad de Chihuahua, la sierra varía en ele- 
vación de 1264 msnm a 1546 msnm, y esta delimitada por las coordenadas geográficas $30^{\circ} 43^{\prime} 53.8^{\prime \prime}$ LN y $106^{\circ} 40^{\prime} 32.9$ " LO (Figura 1).

\subsection{SIERRA LAS AZULES, LAMPAZOS, SONORA}

La Sierra Las Azules se localiza en el municipio de Tepache en el área del mineral de Lampazos, se encuentra aproximadamente a $140 \mathrm{~km}$ al este de la ciudad de Hermosillo, a una altitud que varía entre los 1328 msnm a los 1520 msnm, y se encuentra delimitada por las coordenadas geográficas $29^{\circ} 23^{\prime}$ 23.09" LN y $109^{\circ} 26^{\prime}$ 1.06” LO (Figura 2).

\section{Marco geológico}

\subsection{EL GINTURÓN TEGTÓNICO DE GHIHUAHUA}

El Cinturón Tectónico de Chihuahua se caracteriza por un conjunto de sierras con orientación norte-noroeste, la mayoría de los cuales son estructuras antiformes. Las sierras varían en longitud de 10 hasta $70 \mathrm{~km}$, mostrando un patrón geomorfo- lógico "en echelon", con un tren variable de rectas a sinuosas (en forma de $\mathrm{S}$ ), curvas y retorcidas. La mayoría de las sierras son anticlinales cuyos ejes son verticales, algunas exhiben un vuelco y torsión a lo largo del tren (Monreal y Longoria, 1995). Una característica notable del cinturón tectónico de Chihuahua es la vergencia opuesta de los pliegues y fallas de cabalgadura, es decir, algunos pliegues y fallas vergen hacia el oeste, mientras que otros vergen hacia el este. El patrón morfoestructural de este cinturón tectónico muestra similitudes cercanas a los resultados morfológicos del modelo experimental realizado por Odonne y Vialon (1983), el cual simula un sistema de fallas de desplazamiento horizontal en un basamento rígido bajo una cubierta sedimentaria que es deformada durante el movimiento de dichas fallas (Monreal y Longoria, 1995).

\subsection{LAMPAZOS, SONORA}

Las rocas del Cretácico Inferior expuestas en el área de Lampazos están fuertemente plegadas y falladas. Las estructuras más conspicuas son

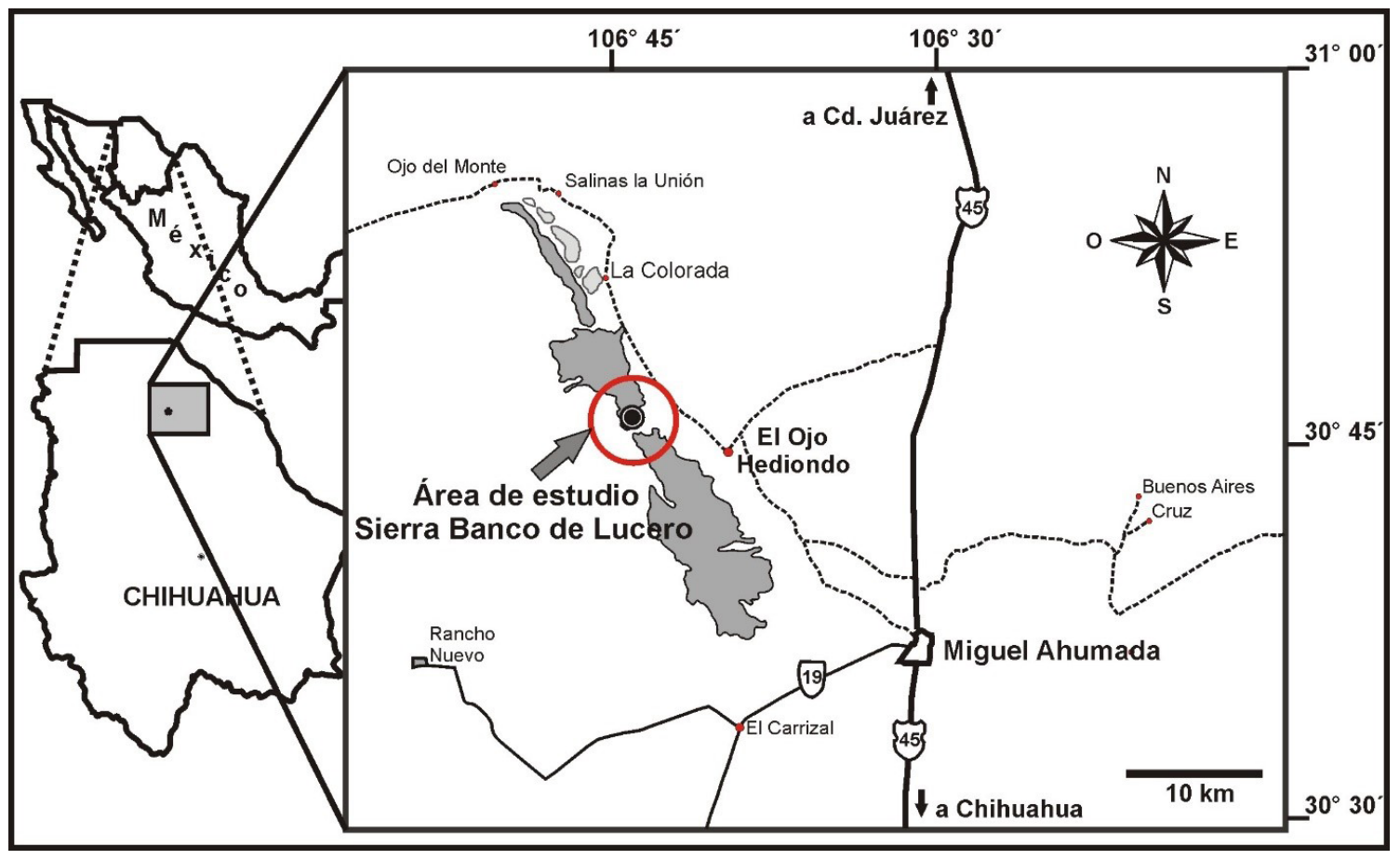

Localización y vías de acceso a la Sierra Banco de Lucero, ubicada al noroeste del municipio de Miguel Ahumada en Chihuahua. 


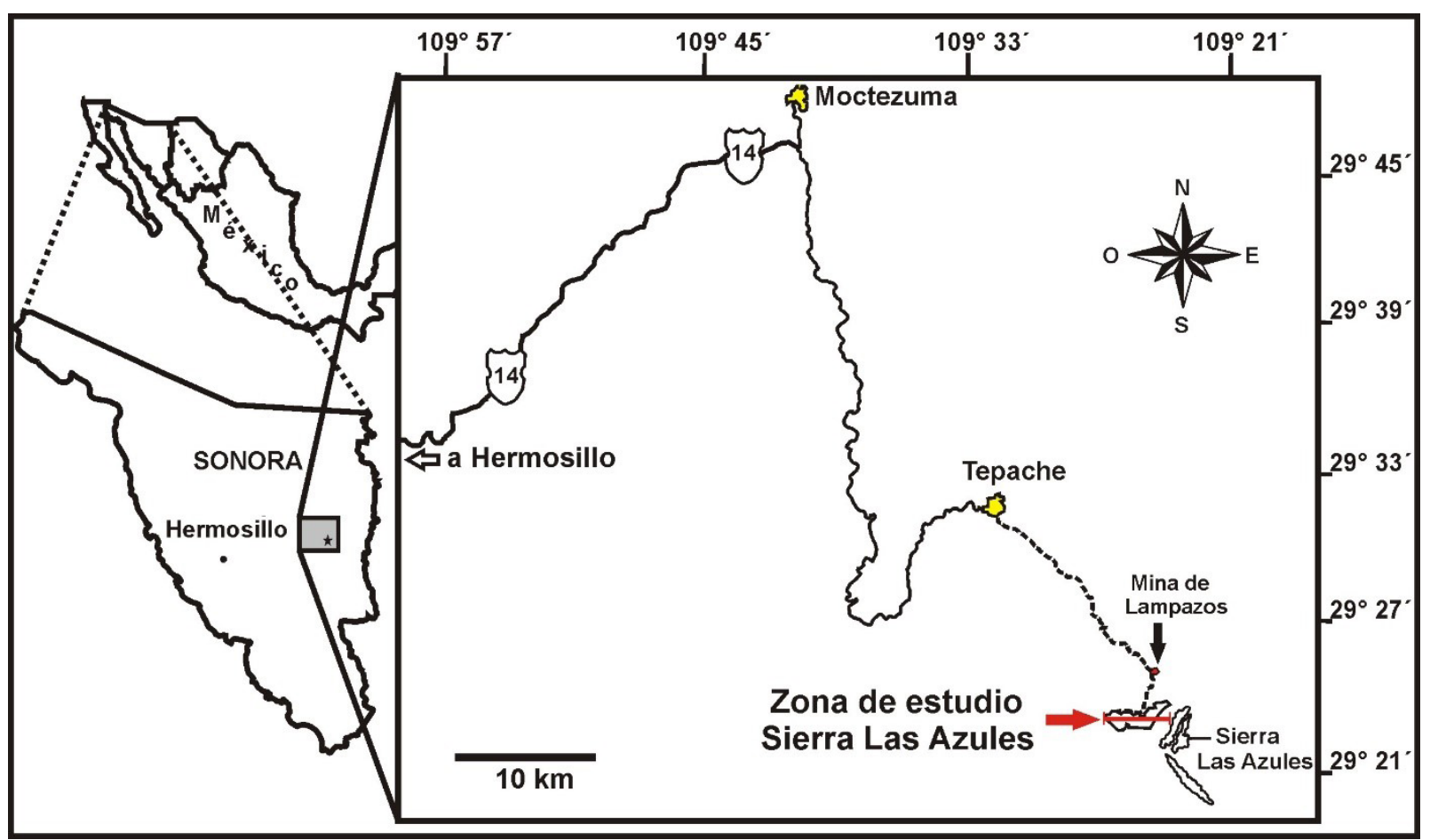

Figura 2 Localización y vías de acceso de la Sierra Las Azules en el área de Lampazos, estado de Sonora, a 4 km al sureste de la Mina de Lampazos.

pliegues isoclinales y en forma de caja a escala kilométrica, así como fallas de cabalgadura, mayormente orientados de norte a sur y noroeste-sureste, las cuales muestran vergencias hacia el noreste y el suroeste. Además, muchos de los pliegues tienen ejes torcidos en forma de "S", y las vergencias de los pliegues cambian en direcciones opuestas de un extremo del pliegue al otro (Monreal y Longoria, 2000).

\subsection{RELAGIONES PALEOGEOGRÁFICAS Y TEGTÓNIGAS}

La sucesión de Lampazos tiene una relación cercana con la sucesión Aptiano-Albiano de la cuenca de Chihuahua, y representa un elemento paleogeográfico intermedio entre la cuenca de Bisbee del norte de Sonora y sur de Arizona y la facies de aguas profundas del mar mexicano (Monreal et al., 1994; Monreal et al., 1995. Además, el análisis estratigráfico llevado a cabo por Monreal y Longoria, (2000) demuestra que la sucesión de Lampazos puede ser litocorrelacionada con sucesiones más conocidas en el noreste Chihuahua (Sierra Banco de Lucero), Coahuila (cañón de Los Chorros) y Nuevo León (cañones de La Boca y Santa Rosa).

La sucesión del Aptiano-Albiano de Lampazos es el resultado de una transgresión global desde el ancestral Golfo de México hacia el mar mexicano y hacia el oeste-noroeste hasta Sonora. Así, esta sucesión expuesta en el centro-oriente de Sonora representa la migración hacia el occidente de la incursión marina desde el ancestral Golfo de México.

\subsection{ESTRATIGRAFÍA DE LA SIERRA BANCO DE LUGERO, GHIHUAHUA}

La Sierra Banco de Lucero está formada, de la base a la cima, por las formaciones Lucero, Ahumada y Loma Plata (Guerrero, 1969; Monreal, 1989) (Figura 3). Aunque estas unidades solo afloran en la Sierra Banco de Lucero, están relacionadas con 
las unidades expuestas al noreste de Chihuahua referidas como formaciones Cuchillo Parado, Benigno, Lagrima, Finlay y Benevides (Monreal y Longoria, 1999).

La Formación Lucero fue descrita por Rodríguez y Guerrero en 1969, está compuesta por aproximadamente 380 metros de caliza arenosa, calcárea; morfológicamente la parte inferior de la formación forma colinas, mientras que la parte superior forma crestas de caliza. La formación ha sido dividida en tres partes: la parte inferior compuesta por caliza de grano fino a mediano en estratos delgados de color gris oscuro, intercalada con estratos medianos de lutita calcárea de color gris oscuro; la parte media compuesta por estratos delgados de caliza y lutita color gris oscuro; y la parte superior contiene estratos medianos de caliza gris oscuro de grano fino. No se observa la base de la Formación Lucero, pero la cima muestra un marcado contacto con la Formación Ahumada. En la Formación Lucero se ha descrito fauna como Colomiella mexicana, Favusella sp., y lenticulinas, de acuerdo con está fauna la posición cronoestratigráfica de la Formación Lucero corresponde al Aptiano superior-Albiano inferior
(Guerrero, 1969). Córdoba (1969) indica que la Formación Benevides, expuesta en las sierras Muleros, Morrión, El Bronce, Cuchillo Parado y área de Santa Elena (Monreal y Longoria, 1999) se podría litocorrelacionar con la Formación Lucero. La Formación Ahumada fue descrita por Rodríguez y Guerrero (1969) para designar 350 metros de una secuencia de estratos gruesas de limolita calcárea que sobreyace a la Formación Lucero y subyace a la Caliza Loma Plata (op. cit.). Se encuentra dividida en tres partes. La parte inferior compuesta por estratos delgados de caliza gris obscuro de grano fino, intercaladas con lutita negra, la parte media contiene capas delgadas de lutita calcárea gris que intemperizan café amarillento intercaladas con estratos delgados de caliza gris obscura de grano fino, la parte superior está formada por estratos medianos de caliza gris obscuro de grano fino. La Formación Ahumada yace concordantemente sobre la Formación Lucero y se encuentra concordantemente debajo de la Caliza Loma Plata (Guerrero, 1969). En esta formación se ha descrito fauna macrofósil que incluye Neithea (bivalvo), Oxytropidoceras trinitense (amonita), y los microfósiles Saccocoma sp., Hedbergella sp, Pithonella

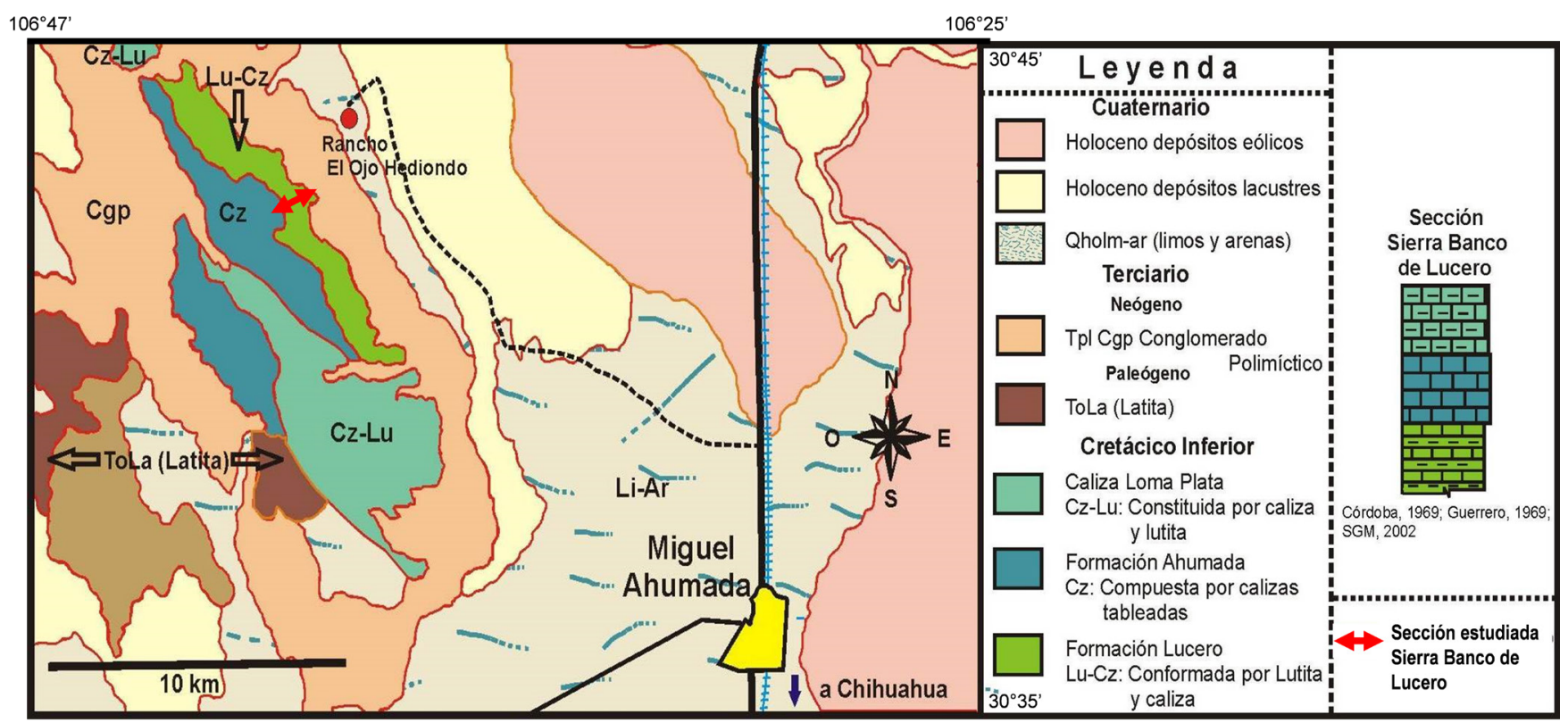

Figura 3 Localización de la sección estudiada en la Sierra Banco de Lucero (marcada con un recuadro rojo). Mapa modificado del Servicio Geológico Mexicano (1999, 2000). 
ovalis (calciesfera), Colomiella sp y Lenticulina sp. (Guerrero, 1969), dada esta asociación Guerrero (1969) asignó a esta formación al Albiano inferior, dado que se extiende hasta la última aparición de Colomiella (que ocurre cerca de la cima de la formación) y a partir de allí el autor considera que se trata del Albiano superior, de la misma manera, ese autor sugiere que la Formación Ahumada es equivalente al miembro inferior de la Caliza Loma Plata en el Cañón Pinto al oeste de Texas (Amsbury, 1957), y con la Formación Lágrima. Así mismo, la parte media de esta formación se litocorrelaciona con La Caliza Finlay y la Formación Benevides al noreste de Chihuahua (Córdoba, 1969).

La Caliza Loma Plata fue asignada por Amsbury (1957) a un cuerpo de roca de $220 \mathrm{~m}$ de caliza nodular gruesa intercalada con lutita y a una caliza gruesa a masiva, en ella se ha identificado una rica macrofauna que incluye Caprinuloidea sp. y Toucasia (rudistas), Kingena (braquiópodo), Enallaster y Holectypus (equinodermos), que refieren la unidad al intervalo Albiano superior - Cenomaniano inferior (Guerrero, 1969).

\subsection{ESTRATIGRAFÍA DE LA SIERRA LAS AZULES, SONORA.}

La secuencia estratigráfica expuesta en el área de Lampazos donde se encuentra la zona de estudio en la Sierra Las Azules está compuesta, estratigráficamente de la base a la cima, por las formaciones El Aliso, Agua Salada, Lampazos, Espinazo del Diablo y Los Picachos (GonzálezLeón, 1988; Monreal y Longoria, 2000) (Figura 4). La Formación El Aliso fue descrita por Herrera y Bartolini (1983) y redefinida por González-León (1988) y Monreal y Longoria (2000). Se divide en tres partes, de la base a la cima: compuesta por lutita negra silícea en capas delgadas y muy delgadas en su base, seguida de caliza en estratos medianos a gruesos, intercalados con lodolita con láminas de caliza, la parte media está compuesta de caliza nodular en capas delgadas a gruesas intercaladas con lutita en estratos delgados; finalmente en la parte superior se observa una alternancia de caliza nodular en capas delgadas y lutitas. Tiene un espesor de 200 metros (Monreal y Longoria, 2000) y ha sido asignada al Barremiano - Aptiano inferior (Scott y González-León, 1991). La Formación Agua Salada fue descrita por Herrera y Bartolini (1983) y redefinida por González-León (1988) y Monreal y Longoria (2000). Está conformada por lutitas negras en estratos delgados a gruesos y caliza en estratos delgados a gruesos, en ella se observan ostras, además de capas de pedernal negro en estratos delgados a gruesos. Se observa pedernal en la base, mientras que en la cima abundan los estratos de lutita con nódulos de caliza. Está formación tiene un espesor de 350 metros y se le asigna al Aptiano inferior (Monreal y Longoria, 2000).

La Formación Lampazos ha sido descrita y caracterizada por diferentes autores, sin embargo, se ha mantenido la descripción original (Solano-Rico, 1970; Herrera y Bartolini, 1983; González-León, 1988; Monreal y Longoria, 2000). Consiste de estratos de caliza intercaladas con lutita e intervalos de arenisca y lodolita. En algunas zonas la unidad tiene un espesor superior a los 600 metros. Ha sido dividida en dos partes, en la base se observa un intervalo de 300 metros de caliza nodular en estratos delgados y medianos, alternando con lutita delgada y con algunos estratos de arenisca fina, mientras que en la cima se observa lutita calcárea negra y gris de 300 metros de espesor y una arenisca fina intercalada con caliza en estratos delgados a medianos (González-León, 1988; Monreal y Longoria, 2000). Ha sido asignada al Aptiano superior - Albiano medio (op. cit.).

La Formación Espinazo del Diablo fue definida por Herrera y Bartolini (1983) y redefinida por González-León (1988) y Monreal y Longoria (2000). Se divide en dos partes, la parte inferior es una secuencia de estratos gruesos a masivos de caliza gris de 15 a 20 metros de espesor, con rudistas, corales y orbitolinidos; la parte superior está formada por una alternancia de caliza nodular 


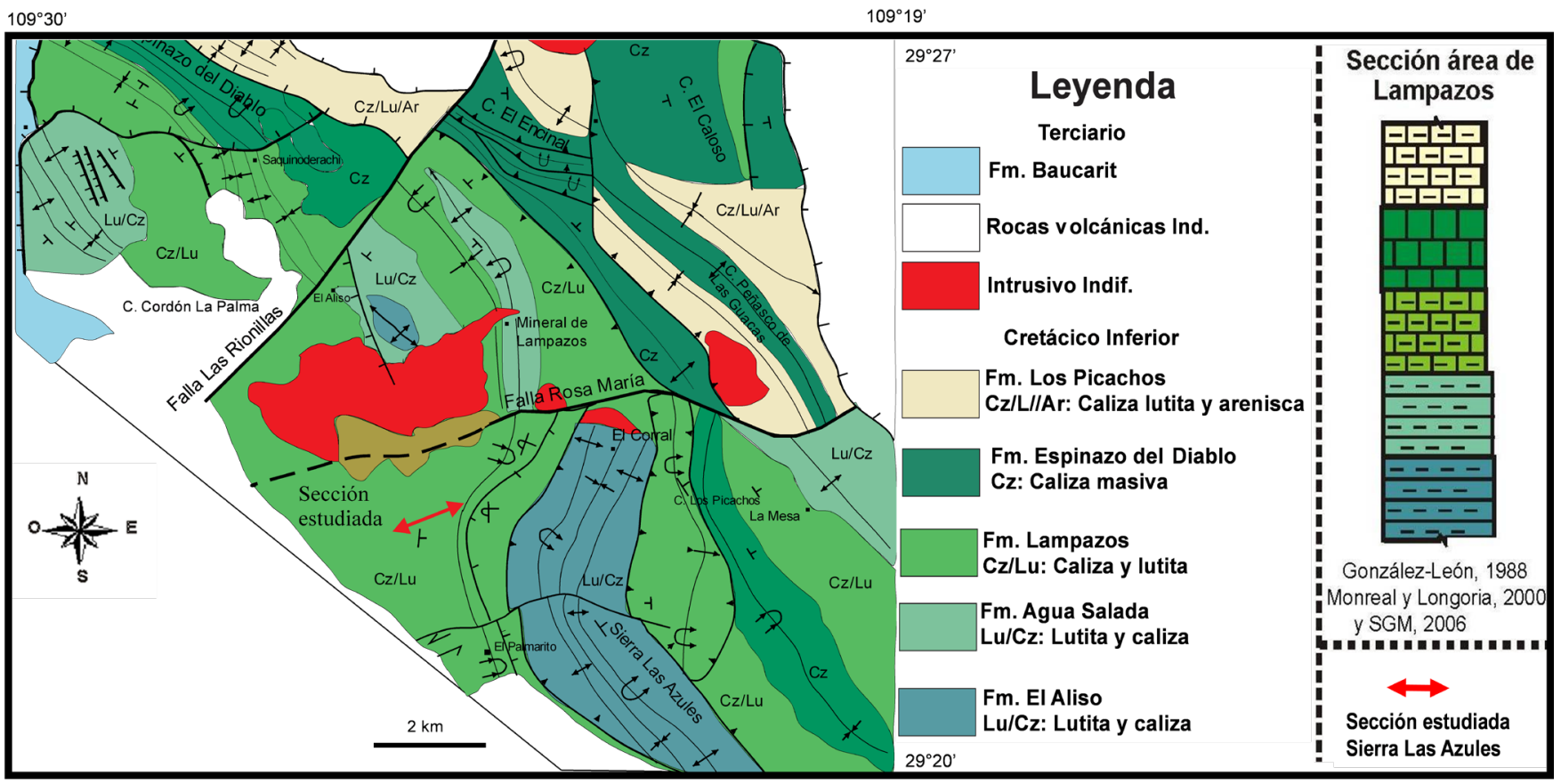

Figura 4 Localización de la sección estudiada en la Sierra Las Azules. Mapa geológico modificado de Monreal y Longoria (2000).

en estratos delgados a medianos intercalada con lutita y arenisca en estratos delgados a gruesos con un espesor de 100 metros. Esta unidad es asignable al Aptiano superior - Albiano medio (Monreal y Longoria, 2000). La Formación Los Picachos fue asignada por Herrera y Bartolini (1983) y fue redefinida por González-León (1988) y Monreal y Longoria (2000). Está constituida por una alternancia de caliza intercalada irregularmente con lutita y arenisca, se observa en la base un conglomerado oligomíctico de clastos de caliza en estratos medianos. Esta unidad tiene un espesor de 400 a 900 metros y es asignable al Aptiano superior - Albiano medio (Monreal y Longoria, 2000).

\section{Método}

\subsection{TRABAJO DE GAMPO}

Las dos secciones estudiadas se midieron con cinta y brújula a distancias de 25 a 50 metros, independientemente si los estratos estuvieran expuestos o cubiertos por vegetación, sin embargo, en los estratos visibles y en cambios litológicos marcados se obtuvieron datos de rumbo, echado, espesor de los estratos, muestras de mano y se realizó la descripción litológica de los estratos, obteniéndose las características físicas tales como tipo de roca, tipo de estratificación, color, estructuras sedimentarias, icnofósiles y macrofósiles, así mismo se tomaron fotografias de la secuencia. Se recolectaron muestras representativas en ambas secciones (en lugares donde se observaron cambios litológicos considerables), para la elaboración de láminas delgadas y así realizar los análisis de microfacies.

\subsection{TRABAJO DE GABINETE}

\subsubsection{ANÁLISIS PETROGRÁFICO Y DE MICROFACIES}

Se elaboraron 45 láminas delgadas de la secuencia estratigráfica expuesta en la Sierra Banco de Lucero, Chihuahua, así como 140 láminas delgadas de muestras del área de Lampazos. Para la determinación petrográfica, análisis de microfacies y contenido de microfósiles, las láminas fueron estudiadas con un microscopio petrográfico modelo BX-40 marca Olympus con objetivos de 4X, 10X y 40X, paralelamente se tomaron micro- 
fotografías con el programa Infinity Analize. Para llevar a cabo la descripción petrográfica se utilizó literatura pertinente (Pettijohn, 1975; MacKenzie y Adams, 1997), así mismo, las muestras analizadas se subdividieron y clasificaron de acuerdo a sus componentes aloquímicos (granos esqueléticos y no esqueléticos), componentes ortoquímicos (matriz o cemento) y componentes terrígenos (materiales no carbonatados), considerados en criterios texturales y composicionales (Dunham, 1962, Folk, 1962).

Se dio especial atención a los componentes paleontológicos tales como foraminíferos planctónicos y bentónicos, colomiélidos y radiolarios, además de considerar otros componentes como fragmentos de equinodermos, ostrácodos y conchas de moluscos. La interpretación paleoambiental de las microfacies se realizó siguiendo la caracterización de microfacies estándar, establecida por Flügel (1982 y 2004), así mismo, para determinar el ambiente de depósito de los paquetes distribuidos en ambas secciones, se consultaron los cinturones de facies de Wilson (1975). Además, se siguió el método utilizado por Longoria y Monreal (1991), que consiste en identificar la ocurrencia de los componentes en las muestras de roca, sean granos esqueléticos o no esqueléticos (ejemplo: intraclastos, peloides, calpionélidos, restos de conchas, equinodermos, etc.). Igualmente se consultó el método de Carozzi (1989) y la guía de rocas carbonatadas de Scholle y Ulmer-Scholle (2003).

El método utilizado para definir las microfacies en este estudio se basa en los criterios estipulados por Flügel (2004) para definir los tipos de microfacies estándar (SMF): 1) tipos y frecuencias de los granos, y asociaciones de granos; 2) tipos de matriz; 3) fábricas deposicionales; 3) tipos de fósiles como grupos dominantes, asociaciones, ocurrencia, si son autóctonos/alóctonos, grupos ecológicos etc.; 4) tipos de texturas deposicionales. Así como en el método utilizado por Longoria y Monreal (1991).

\subsubsection{IDENTIFICACIONES PALEONTOLÓGICAS}

Las determinaciones taxonómicas de los foraminíferos planctónicos y colomiélidos estuvieron a cargo de José Longoria en el Laboratorio de
Microfacies de la Universidad Internacional de Florida, EUA, y se realizaron sobre las mismas láminas delgadas utilizadas para el análisis de microfacies. La taxonomía y biocronometría fue basada en los estudios de carácter micropaleontológico de Longoria (1973, 1974, 1977 y 1984) y de Longoria y Monreal (2009) que se basan principalmente en características tales como la disposición de las cámaras y la forma de la concha, además de parámetros biométricos como la longitud, altura, el ancho y tamaño de las cámaras (Longoria, 1968; Longoria y Gamper, 2002). Para la identificación de colomiélidos se consideraron características como la forma de la lóriga, su tamaño, ausencia o presencia de corona y longitud de esta (Bonet, 1956, Longoria, 1973; Trejo, 1980; Canudo, 2002).

\section{Resultados}

\subsection{LITOESTRATIGRAFÍA}

\subsubsection{SECUENGIA EN LA SIERRA BANCO DE LUCERO, CHIHUAHUA.}

La Sierra Banco de Lucero, tiene una orientación noroeste-sureste, la sección estudiada consta de 800 metros de una alternancia de caliza y en algunos niveles lutita (Figuras 5 y 6 ).

La sección analizada en la Sierra Banco de Lucero está compuesta por las formaciones Lucero y Ahumada (Figuras 7 y 8). La parte baja de la secuencia está conformada por la Formación Lucero, que consiste de: parte inferior compuesta por estratos delgados de caliza intercalada con estratos medianos de limolita calcárea, la parte media está compuesta por estratos delgados de caliza y limolita, finalmente la parte superior contiene estratos medianos de caliza. La parte superior de la secuencia en conformada por la Formación Ahumada, que consiste de: parte inferior compuesta por estratos delgados de caliza, intercaladas con lutita negra, la parte media contiene capas delgadas de lutita calcárea intercaladas con estratos delgados de caliza y la parte superior está formada por estratos medianos de caliza. 

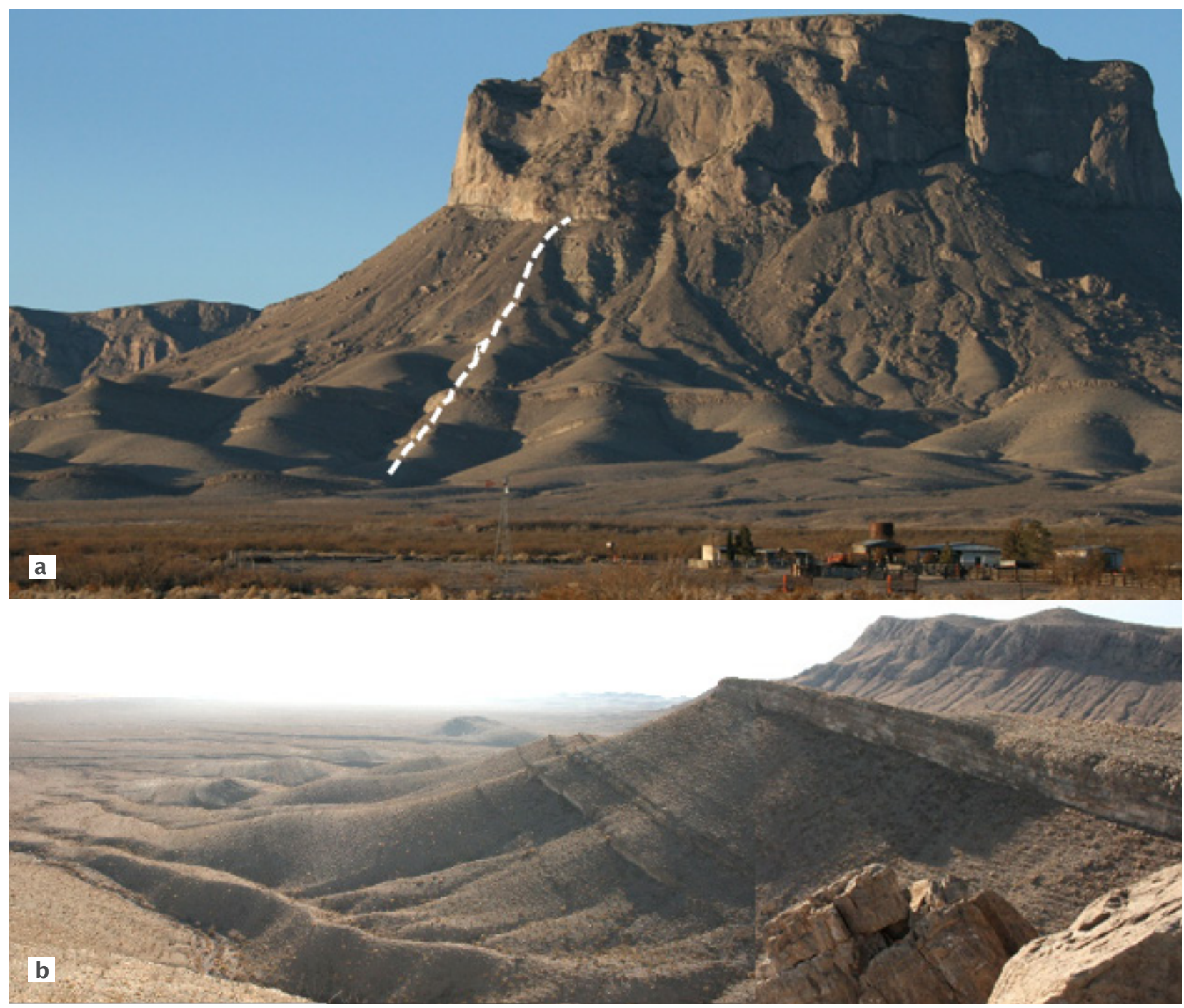

Figura 5 Fotografía del flanco noreste de la Sierra Banco de Lucero, Chihuahua. A) Vista al suroeste mostrando a la sección estudiada (línea blanca discontinua). B) Vista al sureste mostrando la sección estudiada.

\subsubsection{SECUENCIA EN LA SIERRA LAS AZULES, SONORA}

La Sierra Las Azules en el área de Lampazos se localiza en el municipio de Tepache, Sonora. La sección estudiada tiene un espesor medido de 550 metros de una alternancia rítmica homogénea de caliza y lutita, el espesor de los estratos varía de 10 a $30 \mathrm{~cm}$ (Figuras 9 y 10).

La sección estudiada en la Sierra Las Azules, está compuesta por la Formación Lampazos, litológicamente se trata de una secuencia homogénea de caliza intercalada con algunos estratos de lutita calcárea (Figuras 11 y 12). En la parte inferior de la secuencia estudiada se observan calizas arcillosas en estratos medianos a gruesos, de color gris medio que intemperizan a café claro; en algunos intervalos se identifica una intercalación de arcillas. La parte media de la secuencia contiene calizas delgadas de color gris medio a oscuro en superficie fresca, las cuales intemperizan a un color café claro; localmente arcillosa con algunas intercalaciones de margas, se observan también microestilolitos. La parte superior de la sección 


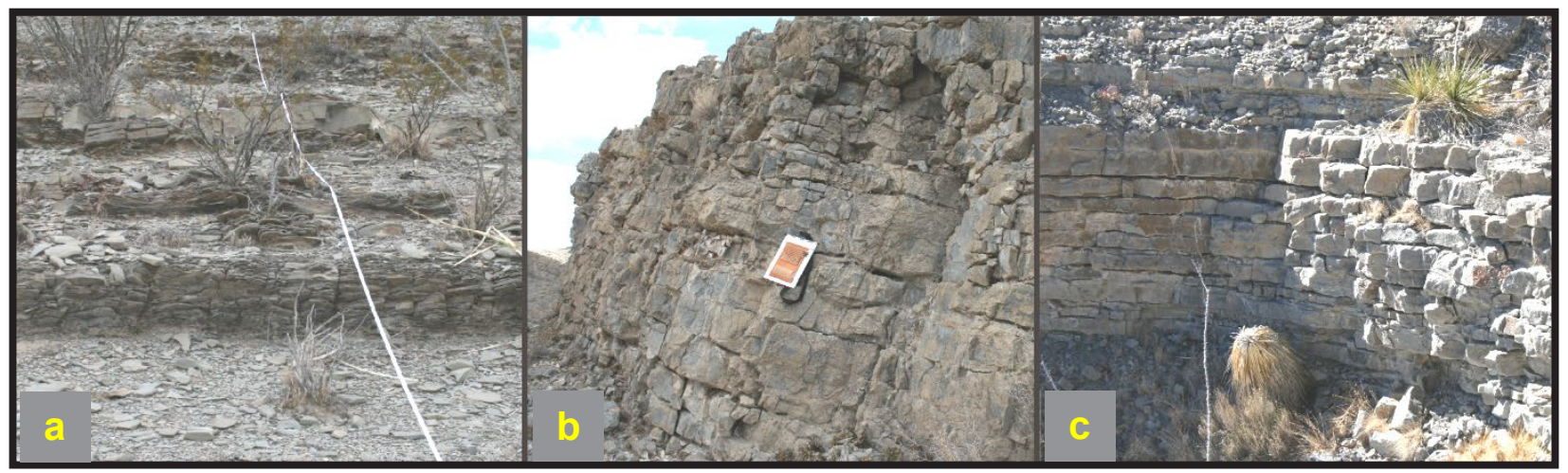

Figura 6 Afloramientos de la secuencia estratigráfica de la sección expuesta en Banco de Lucero. a) Estratos muy delgados de caliza mudstone, b) estratos medianos a gruesos de caliza arenosa, c) estratos delgados de caliza intercalada con lutita calcárea con estratificación paralela y continua.

estudiada contiene una intercalación de calizas laminadas delgadas de color gris oscuro en superficie fresca que intemperizan a un color gris claro; en esta parte de la unidad se observa una mayor intercalación de lutitas delgadas de unos pocos milímetros con vetillas de calcita.

\subsection{MICROFACIES}

Como se mencionó anteriormente, los tipos de microfacies estándar (SMF) utilizados en este estudio se basan en el modelo definido por Flügel (2004) para modelos de sedimentación en plataforma marina carbonatada y de aguas cálidas en latitudes tropicales, donde la ocurrencia y distribución de los tipos de SMF son fuertemente dependientes de la profundidad del agua, y de la configuración y topografía de la plataforma.

Las microfacies propuestas en este estudio se basan en los criterios anteriormente mencionados, sin embargo se considera que una o más de las microfacies propuestas en este estudio pueden corresponder con una sola SMF de Flügel (2004), dependiendo del tipo de contenido fosilífero, es decir que dos o más microfacies definidas en este estudio podrían corresponder a una misma SMF.

A continuación se presentan las microfacies establecidas para las secuencias estudiadas en la Sierra Banco de Lucero, Chihuahua y Sierra Las Azules, Sonora.

\subsection{SIERRA BANGO DE LUGERO, GHIHUAHUA}

\subsubsection{MICROFACIES 1 (MF1)}

Caliza arenosa, wackestone/biomicrita de bioclastos, con foraminíferos planctónicos, ostrácodos, anélidos y otros fragmentos de organismos; cuarzo autigénico. Las galerías de anélidos se interpretan como bioturbación grado 4 según el esquema de Taylor y Goldring (1993), indicativas de plataforma de mar abierto, correspondiendo a la zona ZF2 del esquema de Wilson (1975). Esta microfacies representa la SMF3 de Flügel (2004). Esta microfacies está presente en la muestra L1 y L24 (Tabla 1, Figuras 13-1 a 13-6).

\subsubsection{MICROFACIES 2 (MF2)}

Wackestone/biomicrita de bioclastos con foraminíferos planctónicos y bentónicos (Lenticulina?) y colomiélidos, además de trazas de radiolarios recristalizados y espículas de esponja, indicativos de un ambiente de plataforma de mar abierto, correspondiendo a la zona ZF2 del esquema de Wilson (1975), y representa la SMF3 de Flügel (2004). Esta microfacies está presente en la muestra L2 (Tabla 1, Figuras 13-7 a 13-12).

\subsubsection{MICROFACIES 3 (MF3)}

Wackestone/biomicrita de bioclastos, con abundantes foraminíferos planctónicos, frecuentes ostrácodos, escasos colomiélidos y radiolarios, y 
SW

\section{Sierra Banco de Lucero, Chihuahua}

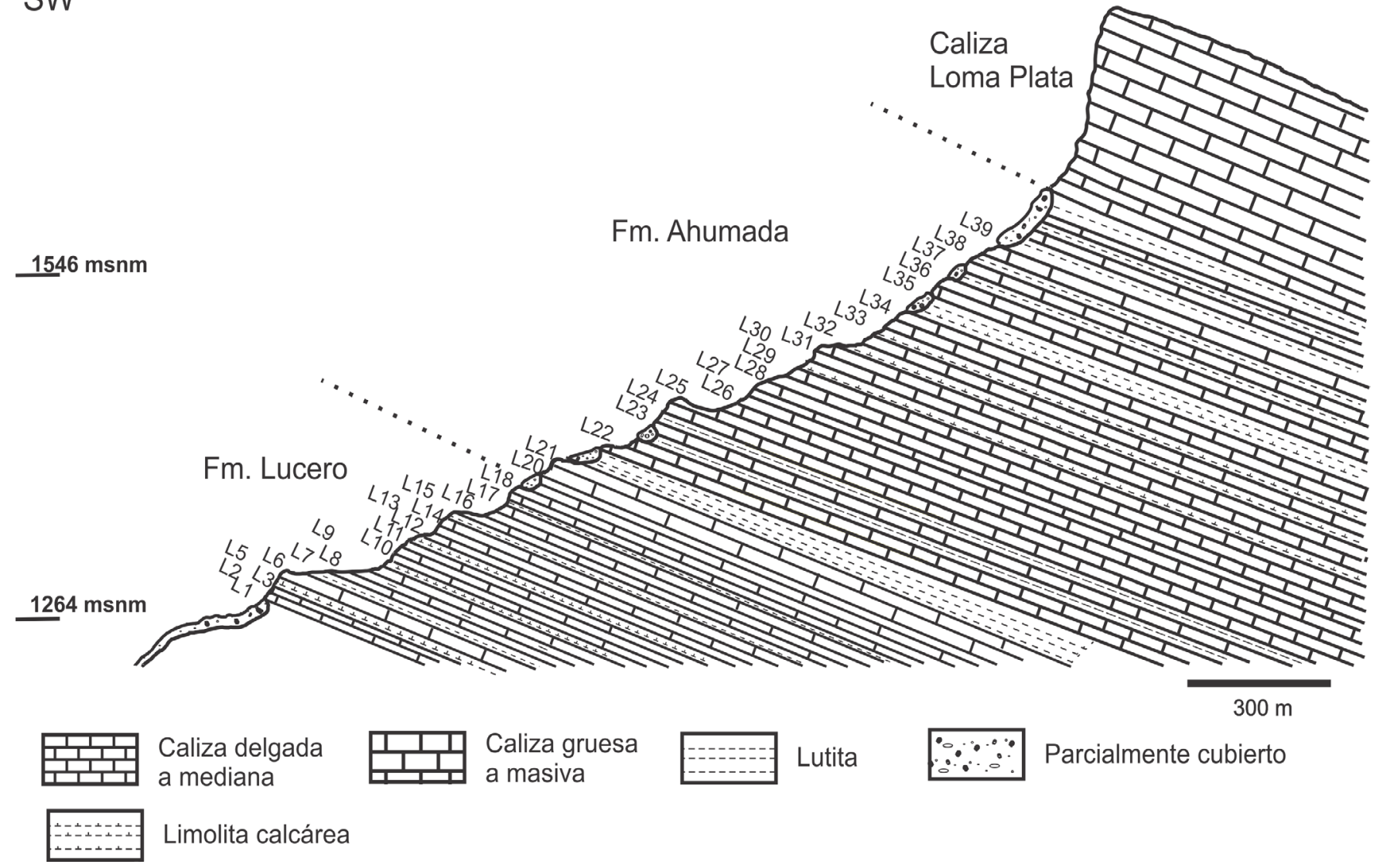

Figura 7 Perfil de la sección estudiada en la Sierra Banco de Lucero, Chihuahua mostrando la litología, las unidades estratigráficas expuestas y las muestras colectadas.

trazas de foraminíferos bentónicos, indicativos de un ambiente de plataforma de mar abierto correspondiendo a la zona ZF2 del esquema de Wilson (1975), y representa la SMF3 de Flügel (2004). Se diferencia de la microfacies 2 (MF2) por la presencia de fauna bentónica en la SMF2. Ésta microfacies está presente en la muestra L3 (Tabla 1, Figuras 13-13 a 13-18).

\subsubsection{MICROFACIES 4 (MF4)}

Wackestone/biomicrita de bioclastos, con abundantes foraminíferos planctónicos, algunos ostrácodos y trazas de crinoides planctónicos, rica en materia orgánica. La abundancia de material terrígeno arci- lloso, lodo calcáreo y la ocurrencia de faunas pelágicas son indicativos de ambientes de baja energía sobre una rampa de poca pendiente en el margen de cuenca, correspondiendo a la zona ZF3 del esquema de Wilson (1975), y representa la SMF3 de Flügel (2004). Ésta microfacies está presente en las muestras L4, L5, L9, L1 0 y L30 (Tabla 1, Figuras 14-1 a 14-6).

\subsubsection{MICROFACIES 5 (MF5):}

Mudstone-wackestone/biomicrita de bioclastos, con abundantes foraminíferos planctónicos, frecuentes colomiélidos y ostrácodos, además de frecuentes crinoides planctónicos y trazas de calciesferúlidos, 


\section{Sierra Banco de Lucero, Chihuahua}

$\stackrel{\pi}{\varepsilon} \frac{\pi}{\frac{\pi}{\alpha}}$

muestras

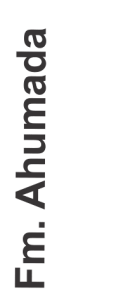

\section{Caliza gruesa a masiva}

Caliza delgada a muy delgada con intervalos de lutita

Caliza delgada, lutitas y capas de caliza mediana

Calizas delgadas intercaladas con lutitas negras Intervalo de calizas delgadas y lutitas con icnofósiles

Calizas delgadas intercaladas con lutitas

Calizas delgadas y medianas

Calizas medianas y delgadas

Caliza gruesa a mediana

Calizas medianas intemperizadas algo dolomitizadas

Calizas delgadas a medianas

Caliza mediana, gruesa y masiva

Caliza delgada

Intercalación de caliza delgada a mediana

Calizas medianas

Caliza delgada con lutitas físiles y calizas muy delgadas *

Caliza delgada a muy delgada

Caliza físil delgada a muy delgada

Caliza físil delgada de color negro con fósiles de crinoides

Caliza delgada y mediana, caliza delgada físil y lutita físil y caliza delgada negra

Caliza mediana a gruesa algo dolomitizada

Lutitas y margas, caliza gruesa y mediana algo dolomitizada

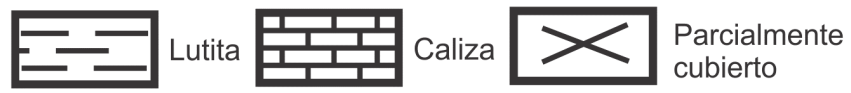


con ligero aporte de material terrígeno en el margen de cuenca, correspondiendo a la zona ZF2 del esquema de Wilson (1975), y representa la SMF3 de Flügel (2004). Esta microfacies está presente en las muestras L6, L7, L11, L12, L15, L14, L17, L20, L25, L26 (Tabla 1, Figuras 14-7 a 14-12).

\subsubsection{MICROFACIES 6 (MF6):}

Mudstone/micrita con pequeños cristales de cuarzo y microestilolitos. Posiblemente corresponde a un ambiente de baja energía en un ambiente de cuenca pelágica y pudiera corresponder a la zona ZF1 del esquema de Wilson (1975), y la SMF2 de Flügel (2004). Ésta microfacies está presente en las muestras L8 (Tabla 1).

\subsubsection{MICROFACIES 7 (MF7):}

Mudstone-wackestone/biomicrita de bioclastos, con abundantes foraminíferos planctónicos, escasos colomiélidos y algunos foraminíferos bentónicos, además de trazas de crinoides planctónicos, y un ligero aporte de materia orgánica. Representa un ambiente de plataforma de mar abierto correspondiendo a la zona ZF2 del esquema de Wilson (1975), y representa la SMF3 de Flügel (2004). Se diferencia de la microfacies 5 en que esta microfacies presenta foraminíferos bentónicos. Esta microfacies está presente en las muestras L13 y L32 (Tabla 1, Figuras 14-13 a 14-18).

\subsubsection{MICROFACIES 8 (MF8):}

Mudstone-wackestone/biomicrita de bioclastos, con solo algunos foraminíferos planctónicos y trazas de foraminíferos bentónicos y ostrácodos, se observa abundante materia orgánica y material terrígeno, indicativos de un ambiente de talud correspondiendo a la zona ZF3 del esquema de Wilson (1975), y representa la SMF3 de Flügel (2004). Se diferencia de la microfacies 4 por contener

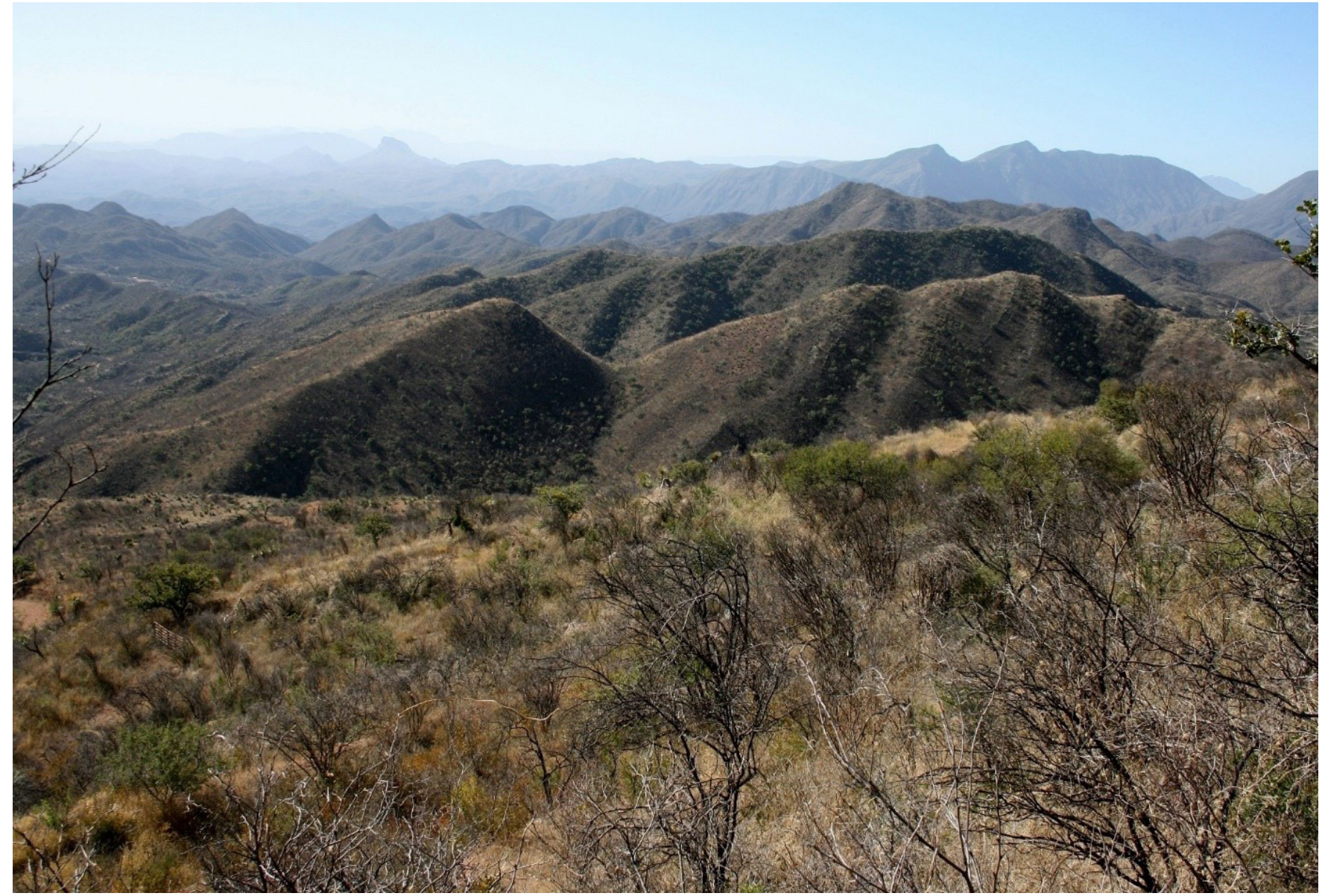

Figura 9 Sección estudiada en la Sierra Las Azules, Sonora, con orientación noreste-suroeste (vista hacia el sur). 


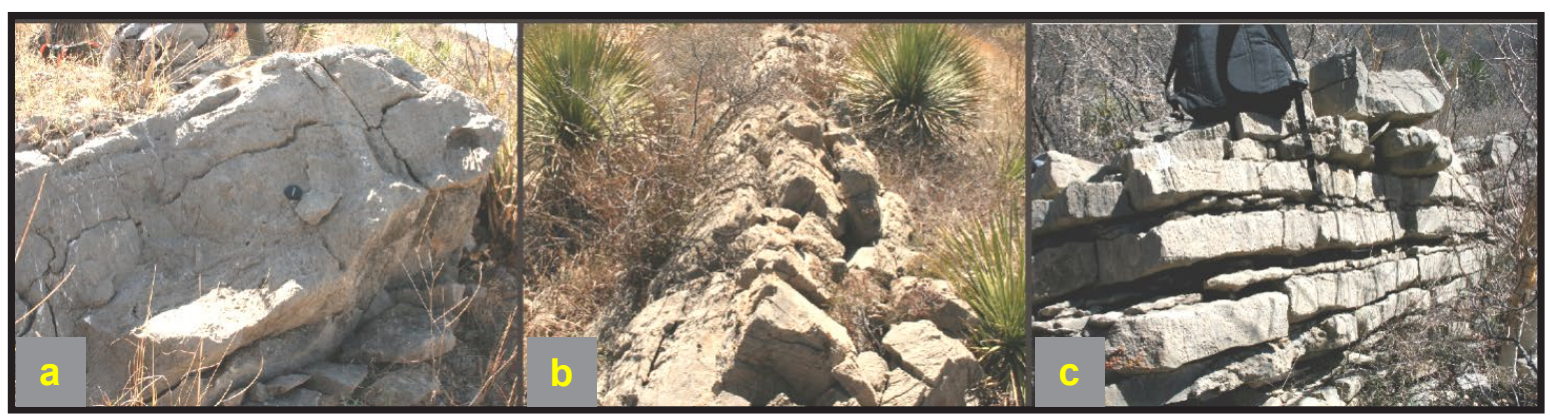

Figura 10 Afloramientos expuestos en la sección estudiada en la Sierra Las Azules. a) Estratos medianos a gruesos de caliza arenosa de la parte inferior de la secuencia, b) estratos delgados de caliza arenosa de la parte media, c) estratos delgados de caliza intercalada con lutita calcárea con estratificación paralela y continua de la parte superior.

foraminíferos bentónicos. Ésta microfacies está presente en las muestras L16, L18, L21, L22, L23

(Tabla 1, Figuras 15-1 a 15-6).

\subsubsection{MICROFACIES 9 (MF9):}

Packstone/biopelmicrita compuesta principalmente por peloides, espículas de esponja, radiolarios, escasos foraminíferos planctónicos y bentónicos, además de trazas de calciesferas, indicativos de un ambiente de talud interior con energía de?media a fuerte, correspondiendo a la zona ZF4 del esquema de Wilson (1975), y representa la SMF5 de Flügel (2004). Esta microfacies está presente en la muestra L19 (Tabla 1, Figuras 15-7 a 15-8).

\subsubsection{MICROFACIES 10 (MF10)}

Mudstone/biomicrita con escasos foraminíferos planctónicos, algunos ostrácodos, radiolarios calcificados, y espinas de equinodermos, con abundancia de terrígenos finos. Representa depositación en una plataforma abierta pelágica correspondiendo a la zona ZF2 del esquema de Wilson (1975), y representa la SMF3 de Flügel (2004). Esta microfacies está presente en las muestras L27, L28 y L31 (Tabla 1, Figuras 15-9 a 15-12).

\subsubsection{MICROFACIES 11 (MF11)}

Packstone/pelmicrita compuesta por abundantes peloides, espículas de esponja (triaxomas) y por escasos foraminíferos bentónicos, además se observan cristales de cuarzo. Representa depositación en áreas restringidas o semi-restringidas como en un ambiente de margen de cuenca (talud), correspondiendo a la zona ZF3 del esquema de Wilson (1975), y representa la SMF2 de Flügel (2004). Esta microfacies está presente en la muestra L29 (Tabla 1, Figuras 15-13 a 15-8).

\subsubsection{MICROFACIES 12 (MF12)}

Mudstone-wackestone/biomicrita de bioclastos, con muy pocos foraminíferos planctónicos y trazas de foraminíferos bentónicos y ostrácodos. Las galerías de anélidos se intepretan como bioturbación grado 4 según el esquema de Taylor y Goldring (1993), indicativas de plataforma de mar abierto, correspondiendo a la zona ZF2 del esquema de Wilson (1975), y representa la SMF3 de Flügel (2004). Se diferencia de la microfacies 1 en que no se presenta evidencia de otros organismos. Esta microfacies está presente en la muestra L33 (Tabla 1, Figuras 15-15 a 15-18).

\subsubsection{MICROFACIES 13 (MF13)}

Mudstone/biomicrita de bioclastos, con frecuentes bivalvos, ostreas y escasos percebes, así como escasos miliólidos y trazas de ostrácodos; con cristales de cuarzo. Los percebes son indicativos de aguas poco profundas con alta energía hidrodinámica, anteriores a la barrera (Ghosh y Sarkar, 2013), indicativos de un ambiente de laguna costera, correspondiendo a la zona ZF7 del esquema de Wilson (1975), y representa la SMF8 de Flügel (2004). Esta microfacies está presente en las muestras L34, L35?, L36, L37?, L38 y L39 (Tabla 1, Figuras 16-1 a 16-6). 


\subsection{MIGROFAGIES DE LA SIERRA LAS AZULES, SONORA}

\subsubsection{MICROFACIES 1 (MF1)}

Mudstone-wackestone/biomicrita de bioclastos, con escasos foraminíferos planctónicos, algunos radiolarios y ostrácodos, indicativos de un ambiente de plataforma de mar abierto correspondiendo a la zona ZF2 del esquema de Wilson (1975) y la SMF8 de Flügel (2004). Esta microfacies está presente en las muestras A16, A30, A32, A33, A40 (Tabla 2, Figuras 16-7 a 16-12).

\subsubsection{MICROFACIES 2 (MF2)}

Wackestone/biomicrita con frecuentes foraminíferos planctónicos, algunos colomiélidos, trazas de ostrácodos planctónicos (Microcalamoides), calciesferas, y algo de materia orgánica. Se diferencia de la microfacies 1 (MF1) dada la presencia de colomiélidos. Representa depositación en un ambiente de margen de cuenca (talud) de baja energía con aporte de materia orgánica bituminosa, debido a la presencia de colomiélidos y frecuentes foraminíferos planctónicos, correspondiendo a la zona ZF3 del esquema de Wilson (1975) y representa la SMF3 de Flügel (2004). Esta microfacies está presente en las muestras A2, A3, A6, A7, A12, A13, A35 (Tabla 2, Figuras 16-13 a 16-18).

\subsubsection{MICROFACIES 3 (MF3)}

Wackestone/biomicrita con frecuentes foraminíferos planctónicos y colomiélidos, trazas de radiolarios y ostrácodos planctónicos (Microcalamoides), además de algunos foraminíferos bentónicos y calciesferas, y contenido de materia orgánica de grano fino, se diferencia de las microfacies $1 \mathrm{y}$ 2 por la presencia de foraminíferos bentónicos. Se observan granos esqueléticos alóctonos como ostrácodos y foraminíferos planctónicos rellenos de calcita granular. Representa depositación en un ambiente pelágico de plataforma de mar abierto, correspondiendo a la zona ZF2 del esquema de Wilson (1975) y representa la SMF10 de Flügel (2004). Esta microfacies está presente en las muestras A1, A5, A9, A10, A11, A14, A15, A25, A27, A31, A34, A36, A37, A38, A39 (Tabla 2, Figuras 17-1 a 17-4).

\subsubsection{MICROFACIES 4 (MF4)}

Wackestone/biomicrita conformada por frecuentes foraminíferos planctónicos, escasos colomiélidos, algunos ostrácodos incluyendo trazas de ostrácodos pelágicos y de espinas de crinoides. Se observa un considerable aporte de material arcilloso y de restos de organismos que pudieron ser arrastrados por corrientes de zonas más someras. Representa depositación en un ambiente de margen de cuenca (talud)

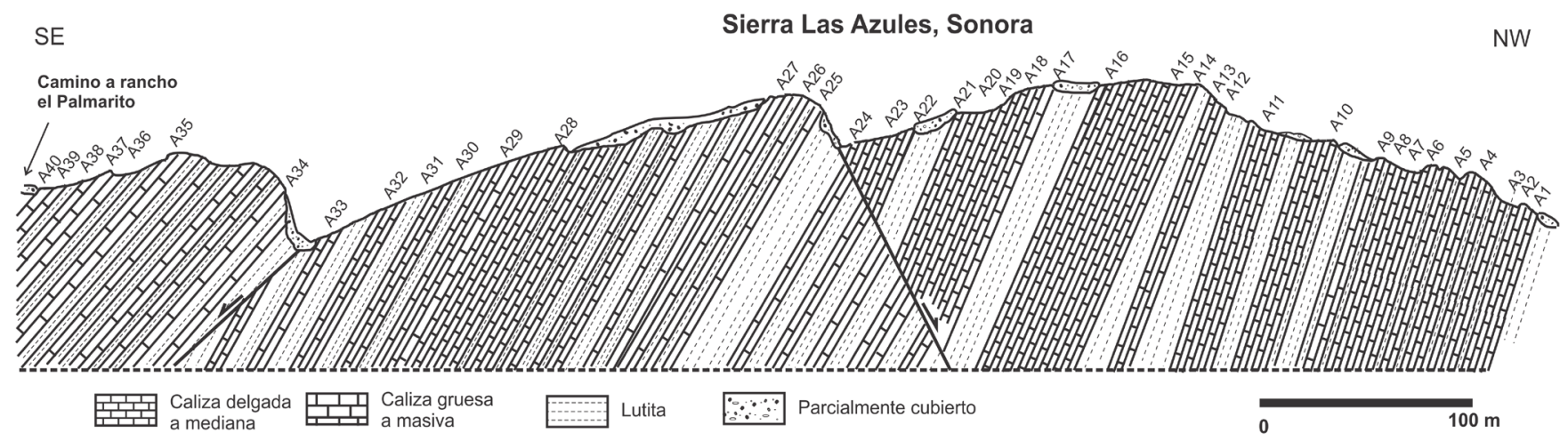

Figura 11 Perfil de la sección estudiada en la Sierra Las Azules, Lampazos, Sonora mostrando la litología, las unidades estratigráficas expuestas y las muestras colectadas. 


\section{Sierra Las Azules, Sonora}

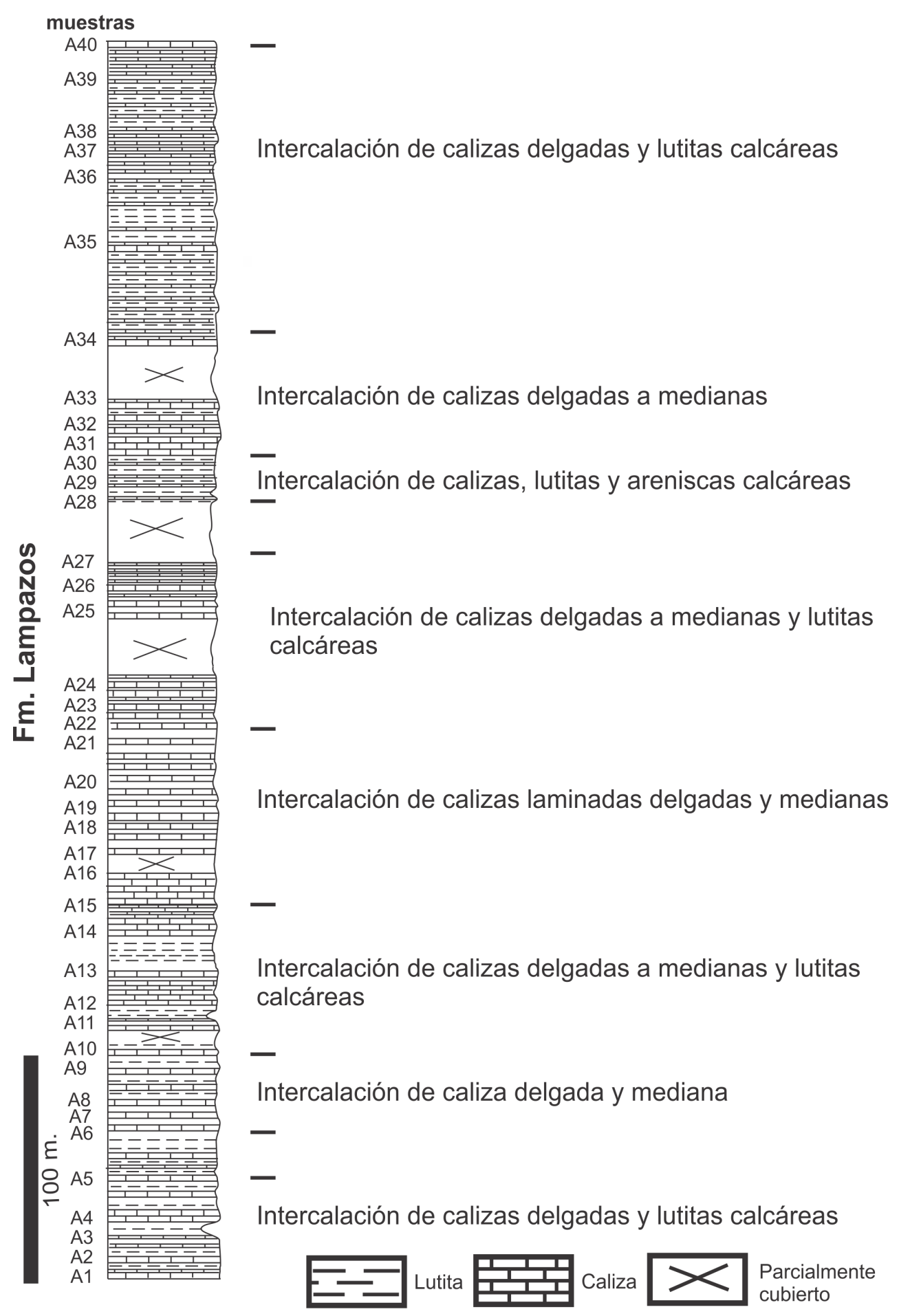

Figura 12 Columna litoestratigráfica de la Formación Lampazos expuesta en la Sierra Las Azules, los números a la izquierda indican la posición de las muestras colectadas para lámina delgada y posterior análisis de microfacies. 
Table 1. Abundancia de aloquímicos en las muestras de la sección de la sierra Banco de Lucero, Chihuahua, se muestran las microfacies. $\mathrm{T}=$ traza (de 0-5 individuos), $\mathrm{R}=$ raro (de 6-10 individuos), $\mathrm{S}=$ escaso (de 11-16 individuos) $\mathrm{F}=$ frecuente (de 17-25 individuos) y $\mathrm{A}=$ abundante (más de 25 individuos).

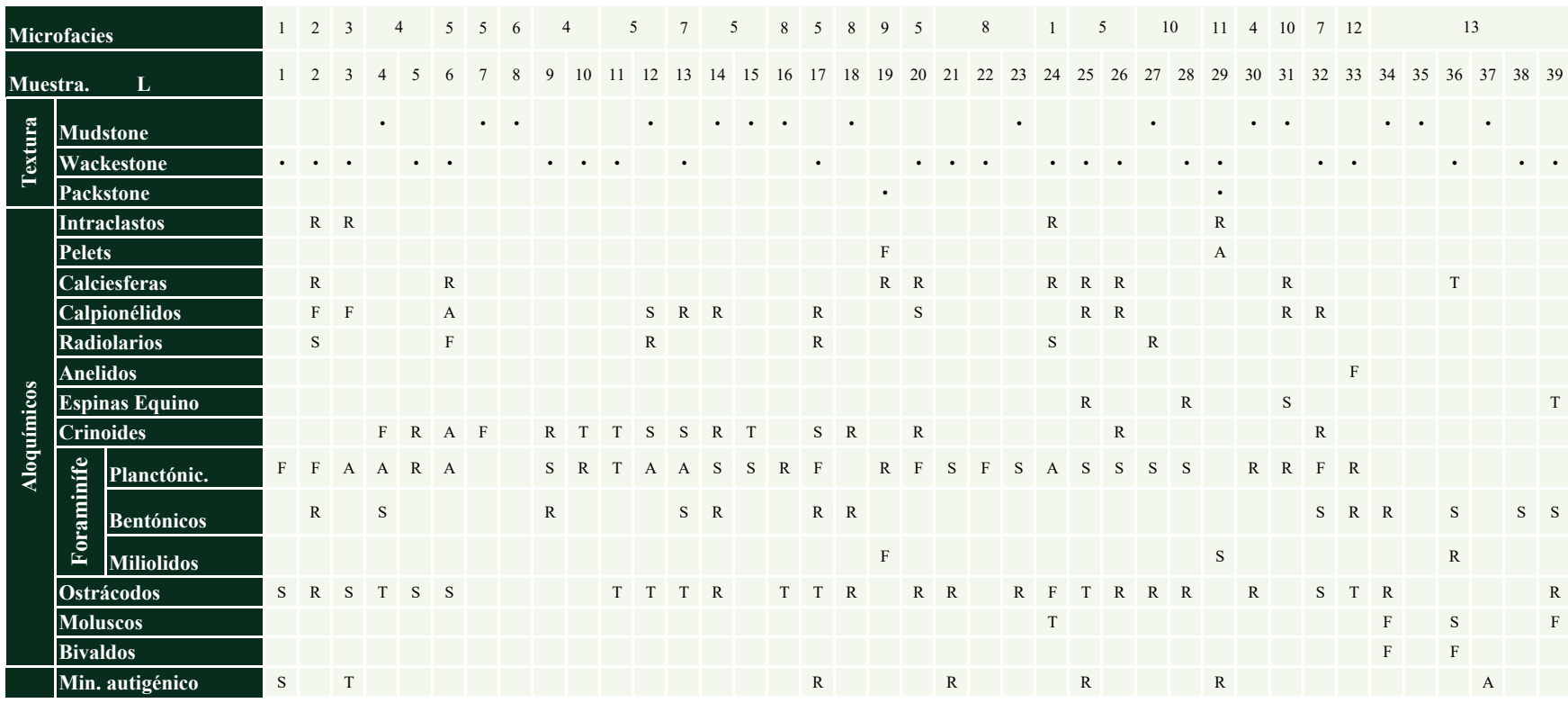

correspondiendo a la zona ZF3 del esquema de Wilson (1975) y representa la SMF3 de Flügel (2004). Esta microfacies está presente en las muestras A4, A18, A20, A26, A29 (Tabla 2, Figuras 17-5 a 17-8).

\subsubsection{MICROFACIES 5 (MF5)}

\section{Wackestone-packstone/biomicrita}

conformada por intraclastos y extraclastos, foraminíferos planctónicos, algunos colomiélidos, ostrácodos y radiolarios, trazas de foraminíferos bentónicos, amonites, anélidos y calciesferas. La asociación de amonites, anélidos y de foraminíferos planctónicos es indicativo de un ambiente pelágico, se observa textura de acumulación de aloquímicos por corrientes, correspondiendo a la zona ZF3 del esquema de Wilson (1975) y representa la SMF4 de Flügel (2004). Esta microfacies está presente en las muestras A8, A17, A19 (Tabla 2, Figura 17-9 a 17-12).

\subsubsection{MICROFACIES 6 (MF6)}

Wackestone-packstone/biomicrita de intraclastos y extraclastos, foraminíferos planctónicos, algunos foraminíferos bentónicos, ostrácodos planctóni- cos y ostrácodos bentónicos, trazas de colomiélidos y trazas de gasterópodos, así como muy pocos radiolarios, se observa mucha materia orgánica, fragmentos de organismos, y algunos anélidos. Esta asociación indica un ambiente turbidítico y de arrastre debido a la presencia de foraminíferos rotos y extraclastos. Se diferencia de la microfacies 5 en que aquí se observa una mayor cantidad de material terrígeno de grano fino, extraclastos y restos de organismos que pudieron ser acarreados por corrientes desde partes más someras de la plataforma. Representa depositación en un ambiente de plataforma de mar abierto, correspondiendo a la zona ZF2 del esquema de Wilson (1975) y representa la SMF10 de Flügel (2004). Esta microfacies está presente en las muestras A21, A22, A23, A24 (Tabla 2, Figuras 17-13 a 17-15).

\subsubsection{MICROFACIES 7 (MF7)}

Wackestone/biomicrita compuesta por trazas de foraminíferos planctónicos, fragmentos de conchas, trazas de gasterópodos, presencia de intraclastos y arenas finas granulares y gran cantidad 


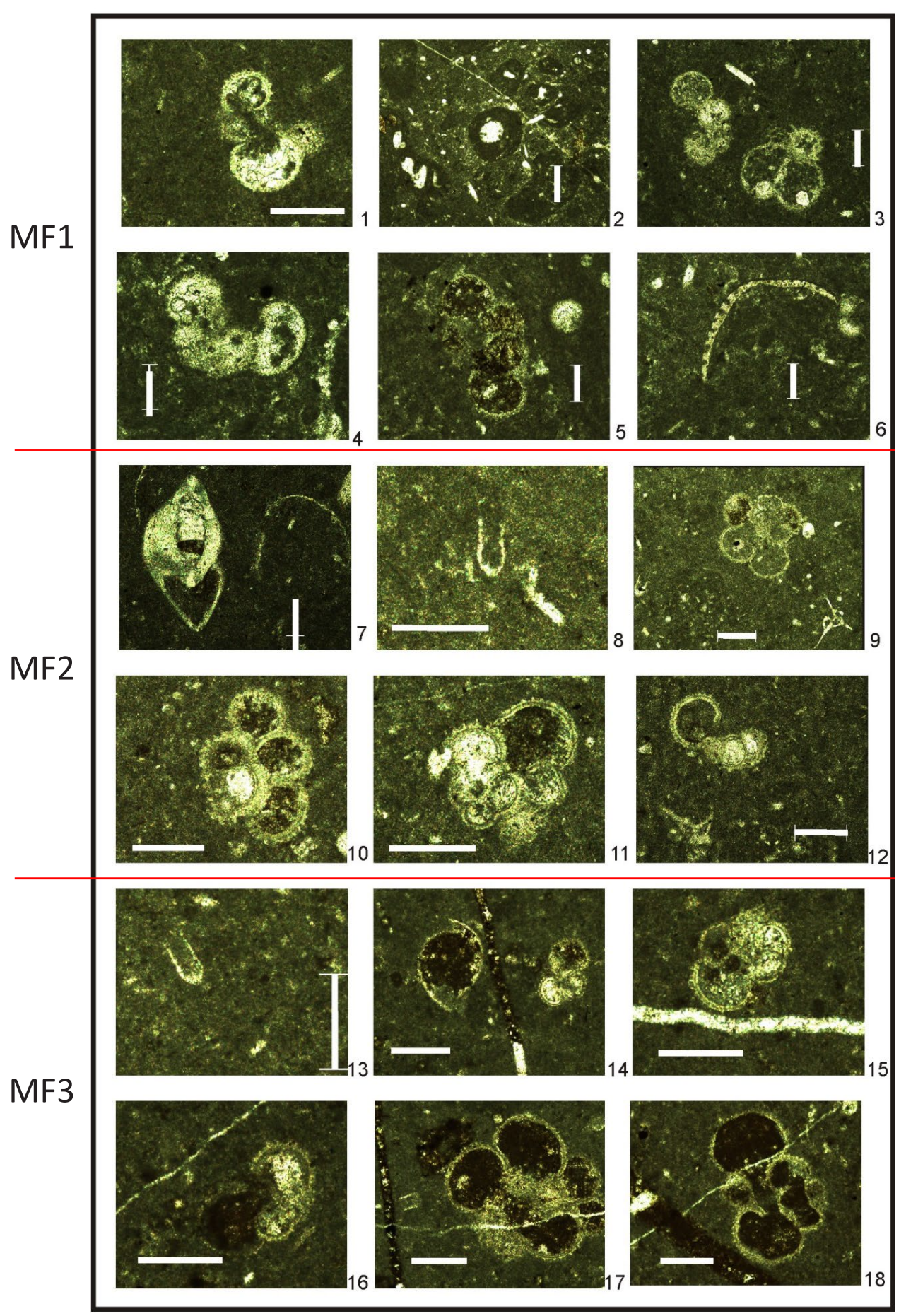

Figura 13 Fotomicrografías de las Microfacies en la Sierra Banco de Lucero. Microfacies 1: 1) Hedbergella cf. delrioensis (muestra L1); 2) Anélidos (muestra L24);3) Hedbergella delrioensis (muestra L24); 4) Hedbergella. cf. delrioensis (muestra L24); 5) Biticinella cf. breggiensis (muestra L24); 6) Ostrácodo planctónico, Microcalamoides diversus (muestra L24). Microfacies 2: 7) Lenticulina sp., luz polarizada (muestra L2); 8) Colomiella mexicana (muestra L2); 9) Favusella sp, espícula de esponja? (triaxoma) y Colomiella sp. (muestra L2); 10) Favusella scitula (muestra L2); 11) Favusella cf. washitensis (muestra L2); 12) Hedbergella cf. trocoidea y espícula de esponja (triaxoma) (muestra L2). Microfacies 3: 13) Colomiella recta (muestra L3); 14) Hedbergella cf. gorbachikae y ostrácodo (muestra L3); 15) Favusella scitula (muestra L3); 16) Favusella washitensis (muestra L3); 17) Globigerinelloides ferreolensis y Colomiella sp. (muestra L3); 18) Ticinella cf. breggiensis (muestra L3). Escala en todas las microfotografías $=200 \mu \mathrm{m}$. 
Table 2. Abundancia de aloquímicos en las muestras de la sección de la sierra Las Azules, Sonora, se muestran las microfacies. $\mathrm{T}=$ traza (de 0-5 individuos), $\mathrm{R}=$ raro (de 6-10 individuos), $\mathrm{S}=$ escaso (de 11-16 individuos) $\mathrm{F}=$ frecuente (de 17-25 individuos) y $\mathrm{A}=$ abundante (más de 25 individuos).

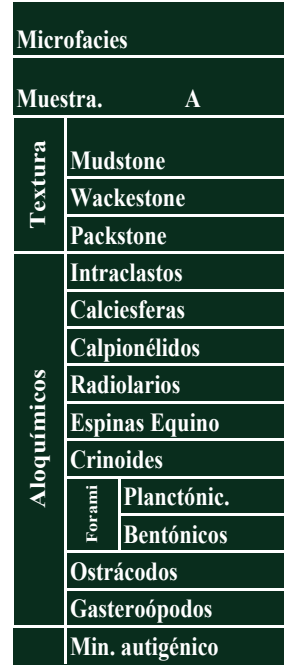

de materia orgánica. Representa depositación en un ambiente de margen de cuenca (talud) correspondiendo a la zona ZF3 del esquema de Wilson (1975) y representa la SMF2 de Flügel (2004). Esta microfacies está presente en la muestra A28 (Tabla 2).

\section{Discusión}

El análisis de la litoestratigrafía, microfacies y contenido de microfósiles de las secciones estratigráficas del Aptiano superior-Albiano inferior estudiadas en Chihuahua y Sonora permiten hacer comparaciones muy objetivas entre ambas localidades, lo cual arroja información del ambiente de depósito y las relaciones temporales y paleogeográficas que las relacionan entre sí, así como la relación que ellas guardan con otras secciones de diferentes localidades en el norte y noreste de México, las cuales se discuten a continuación.

En ambas secciones estudiadas la caliza micrítica es predominante, casi en su totalidad, con algunos intervalos de caliza arenosa, caliza arcillosa y lutita. La sección Aptiano-Albiano expuesta en la Sierra Banco de Lucero ha sido asignada a las Formaciones Lucero y Ahumada, mientras que la sección expuesta en la Sierra Las Azules corresponde a la Formación Lampazos. La litología dominante en ambas secuencias, corresponde a calizas bioclásticas que indican períodos de depósito de sedimentos marinos finos, cíclicos y homogéneos durante largos períodos de tiempo.

En ambas secciones las rocas predominantes corresponden a biomicritas, siendo más abundante el wackestone, seguido de mudstone y rara vez se observa packstone. Las microfacies evidencian depositación casi homogénea de baja energía, únicamente en la parte alta de la secuencia en la Sierra Banco de Lucero se observa packstone con un mayor aporte de material biogénico proveniente de restos de conchas de moluscos, y en algunos casos están presentes galerías de anélidos (gusanos) y pseudopeloides indicativos de retrabajo del lodo calcáreo en ambiente de alta energía.

La Formación Agua Salada, de acuerdo con Scott y González (1991) es asignable al Aptiano superior, pero Monreal y Longoria (2000) encontraron al foraminífero Caucasella hauterivica, además de 


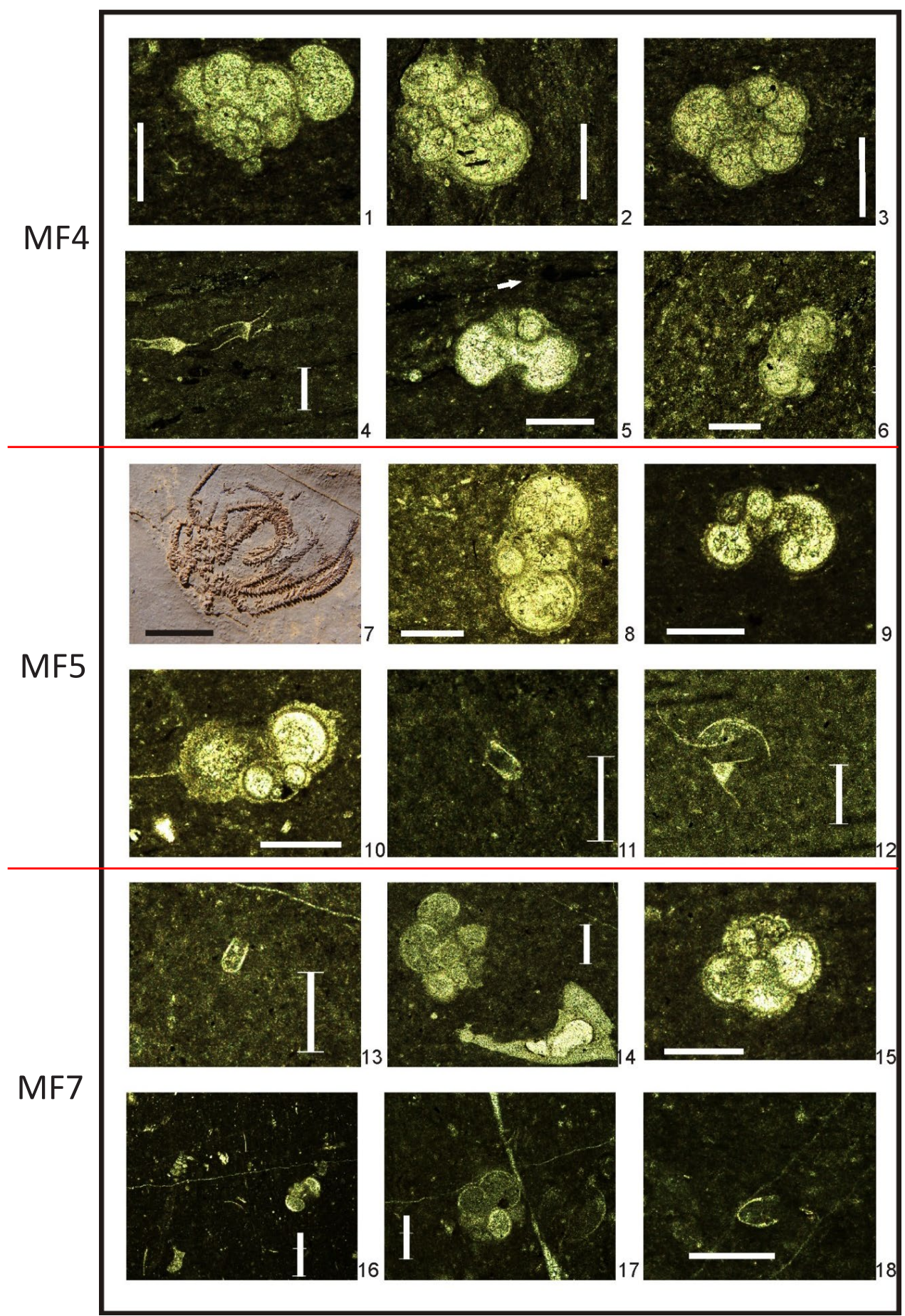

Figura 14 Fotomicrografías de las Microfacies en la Sierra Banco de Lucero. Microfacies 4: 1) Favusella scitula (muestra L4); 2) cf. Favusella (muestra L4); 3) cf. Globigerinelloides (muestra L4); 4) Trazas de crinoides planctónicos (muestra L5); 5) Favusella washitensis (muestra L5); 6) Paraticinella eubejaouaensis (muestra L30). Microfacies 5: 7) Fotografía en muestra de mano de crinoide planctónico, Saccocoma sp. (muestra L7); 8) Favusella scitula (muestra L12); 9) Hedbergella delrioensis, luz polarizada (muestra L12); 10) Ticinella bejaouaensis (muestra L12); 11) Colomiella recta (muestra L15); 12) Ostrácodos y restos de crinoide planctónico (muestra L15). Microfacies 7: 13) Colomiella recta (muestra L13); 14) Hedbergella trocoidea y traza de espina de crinoide (muestra L13); 15) Favusella washitensis (muestra L13); 16) Wackestone, Ticinella sp, luz polarizada (muestra L32); 17) Favusella sp., luz polarizada (muestra L32); 18) Colomiella mexicana, luz polarizada (muestra L32). La escala en todas las microfotografías $=200 \mu \mathrm{m}$, excepto en foto $7=1 \mathrm{~cm}$. Las flechas blancas en las microfotografías indican la dirección de la corriente. 


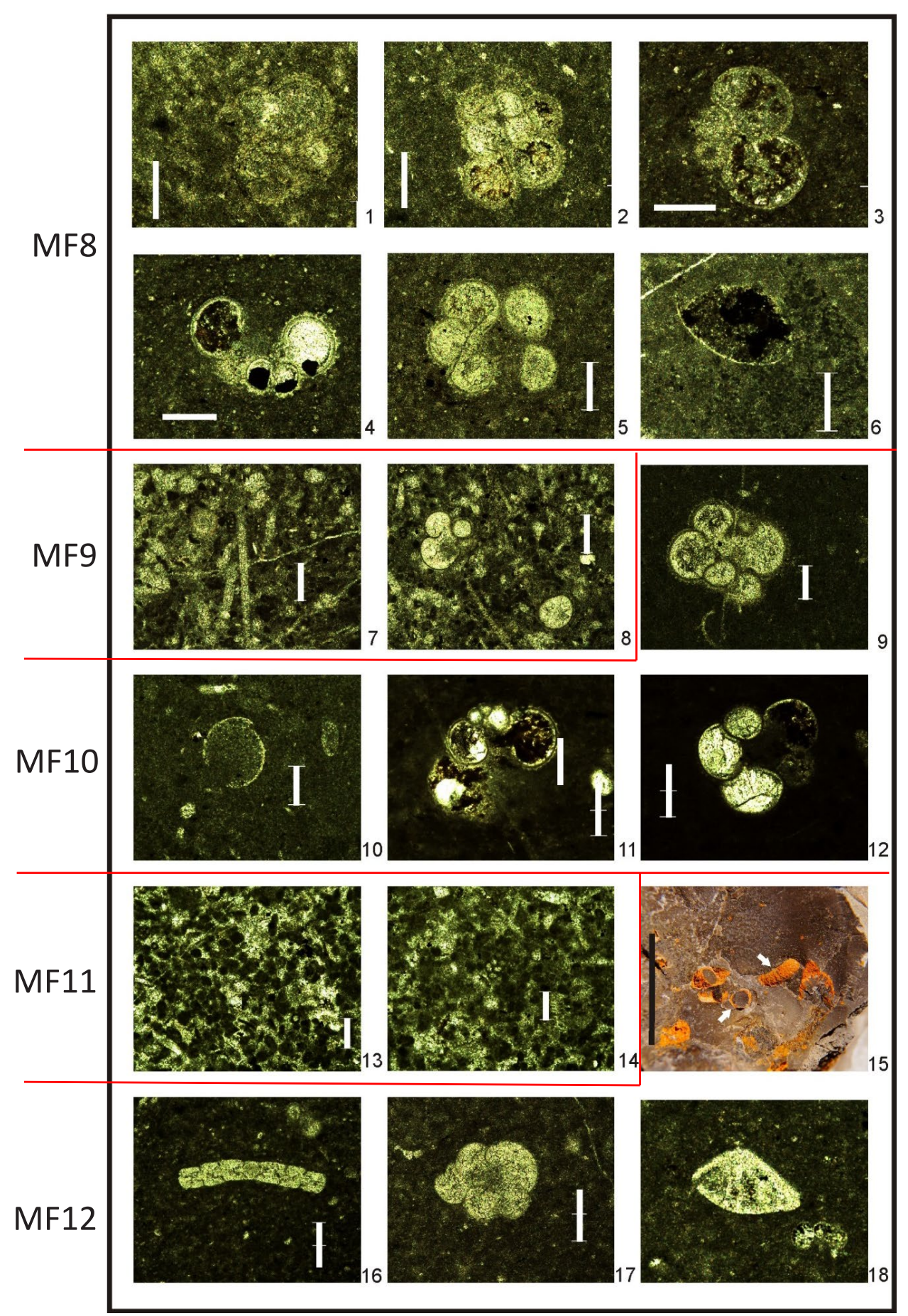

Figura 15 Fotomicrografías de las Microfacies en la Sierra Banco de Lucero. Microfacies 8: 1) Favusella washitensis (muestra L21); 2) Foraminífero planctónico no identificado (muestra L21); 3) Favusella cf. washitensis (muestra L22); 4) Ticinella primula, estructura geopetal (muestra L22); 5) Hedbergella cf. trocoidea (muestra L23); 6) Ostrácodo (muestra L23). Microfacies 9: 7) Espículas de esponja (muestra L19); 8) Foraminíferos planctónicos y espículas de esponja (muestra L19). Microfacies 10: 9) Favusella washitensis en matriz de micrita uniforme (muestra L27); 10) Ostrácodos (muestra L27); 11) Ticinella cf. breggiensis (muestra L28); 12) Globigerinelloides sp. luz polarizada (muestra L28). Microfacies 11: 13) Pelmicrita, packstone (muestra L29); 14) Miliólido y espículas de esponja (triaxoma) (muestra L29). Microfacies 12: 15) Fotografía de muestra de mano, galerías de gusanos (bioturbación) sobre roca micríta (muestra L33); 16) Trazas de galerías de gusano en lámina delgada (muestra L33); 17) Favusella sp. (muestra L33); 18) Lenticulina sp. y foraminífero planctónico (muestra L33). Escala en todas las microfotografías $=200 \mu \mathrm{m}$, escala en la foto. $15=1 \mathrm{~cm}$. 
microfauna de radiolarios y foraminíferos planctónicos que en conjunto la refieren al Aptiano inferior y a un ambiente de mar abierto pelágico; similarmente, la Formación Lampazos del Aptiano superior-Albiano medio, corresponde a un ambiente de mar abierto pelágico.

Las secciones estudiadas pueden cronocorrelacionarse con la parte superior del Miembro Caliza La Borrega y el Miembro Caliza Otates de la Caliza Tamaulipas de la Sierra de Tamaulipas, que corresponden a la localidad tipo y estratotipo de esta unidad. La Formación Lucero en la Sierra Banco de Lucero es similar a la Formación Cuchillo descrita por López-Doncel et al. (2005) en la Sierra del Cartucho (noroccidente de Chihuahua), asignada al Aptiano-Albiano, y litológicamente son similares dado que son calizas con estratificación mediana a masiva intercaladas con lutitas.

En las secuencias estratigráficas estudiadas, se identificaron los fósiles índice Ticinella bejaouaensis, Colomiella recta y C. mexicana, por lo que es posible restringir estas secuencias al Aptiano superior (Clansagesiano superior)-Albiano inferior, y a la Biozona K-13 a la K14 de acuerdo con el esquema bioestratigráfico de Longoria (1984) (Figura 18). Las secciones estudiadas pueden biocorrelacionarse con la parte inferior de la Caliza Tamaulipas, por la presencia de Colomiella recta, C. mexicana, Hedbergella, globigerínidos y radiolarios calcificados, los cuales indican ambientes pelágicos de aguas profundas y de baja energía para el Aptiano, de la misma manera, las secciones se correlacionan con la parte media y superior del Miembro Canova de la Caliza Mural expuesta en el Cerro el Caloso "Pitaycachi" en Sonora, descrita por González-León et al. (2008), dada la presencia de Colomiella mexicana, Hedbergella delrioensis, Favusella washitensis y otros foraminíferos planctónicos en dichas localidades.

Ambas secciones presentan asociaciones faunísticas muy similares, representadas principalmente por foraminíferos planctónicos, colomiélidos y foraminíferos bentónicos, aunque se observa una mayor diversidad de organismos en la sección de la Sierra Banco de Lucero, dominada por forami- níferos planctónicos, seguida de formas bentónicas, colomiélidos, moluscos y galerías de anélidos. La variedad de organismos presentes en esta localidad, se debe a que existió una mayor variación en la profundidad de los ambientes (Figura 19). Aunque la secuencia de la Sierra Las Azules presenta una mayor abundancia de foraminíferos planctónicos, además de una mayor abundancia de formas bentónicas y radiolarios, que representan ambientes pelágicos de mar abierto. La fauna dominante en la secuencia de la Sierra Las Azules está representada por foraminíferos especialistas (trocoespirales), lo que permite hablar de condiciones estables en cuanto al ambiente, dado que de acuerdo con Coccioni y Luciani (2004), si las condiciones ambientales son inestables (eutróficas), dominarían faunas oportunistas (foraminíferos biseriales), como se observó en la secuencia de la Sierra Banco de Lucero.

En ambas localidades se observan pequeñas diferencias en los ambientes de depósito para el intervalo Aptiano superior-Albiano inferior, dado por las variaciones en el nivel del mar que afectaron a dichas localidades, pero no existe duda sobre la conexión respecto de la continuidad lateral entre ambas secuencias, por lo que estas pequeñas diferencias se reflejan en las microfacies y en menor grado, a nivel taxonómico.

Las microfacies en ambas localidades, permiten inferir los ambientes de depósito durante el intervalo Aptiano-Albiano. Para el caso de la secuencia de Banco de Lucero, los ambientes identificados varían principalmente desde plataforma de mar abierto hasta talud interior, y lagunar en la parte superior (Figura 19). Las microfacies reconocidas en la Sierra Las Azules, corresponden únicamente a ambientes que van desde plataforma de mar abierto hasta margen de cuenca (talud), a diferencia de las microfacies identificadas en la sección de Chihuahua, donde se observa mayor estabilidad en cuanto a los ambientes de depósito, aunado a un mayor incremento en los organismos planctónicos como los foraminíferos planctónicos y radiolarios, además de un aporte considerable de materia orgánica proveniente de ambientes más someros. 


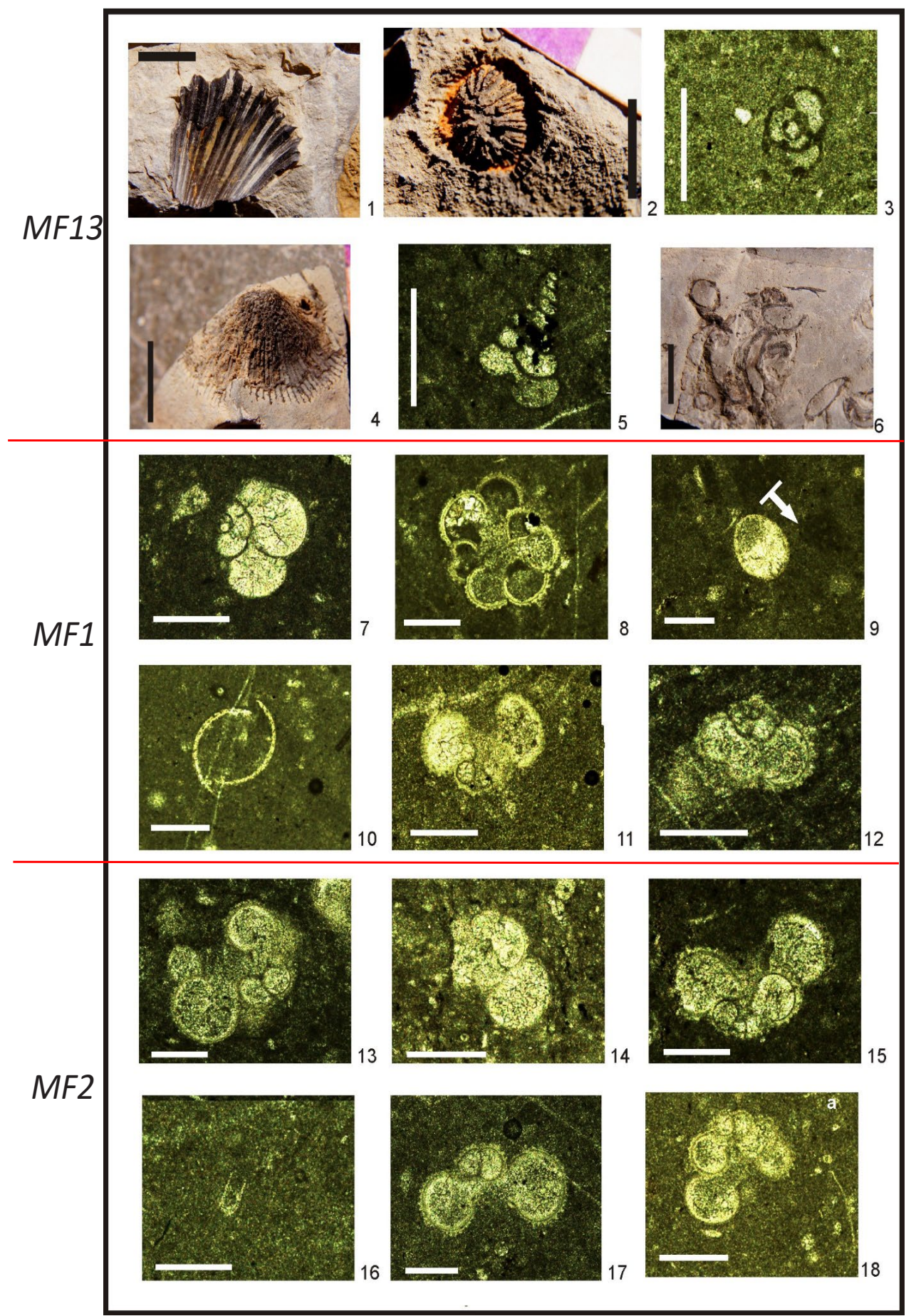

Figura 16 Fotomicrografías de las Microfacies en la Sierra Banco de Lucero. Microfacies 13: 1) Fragmento de bivalvo (muestra L34); 2) Percebe (muestra L34); 3) Miliólido (clave lámina L36); 4) Percebe (muestra L36); 5) Rotálido bentónico (muestra L39), luz polarizada; 6) Fragmentos de concha de moluscos (muestra L39). Fotomicrografías de las Microfacies en la Sierra Las Azules. Microfacies 1: 7) Ticinella? sp (muestra A33); 8) Globigerinelloides sp., cámara rellena de calcita granular (muestra A30); 9) Ostracodo, estructura geopetal, la flecha indica la dirección de los sedimentos (muestra A30); 10) Microcalamoides sp. (muestra A32); 11) Hedbergella cf. gorbachikae (muestra A33); 12) F. scitula, luz polarizada (muestra A33). Microfacies 2: 13) Hedbergella delrioensis (muestra A2); 14) cf. Favusella (muestra A3); 15) Paraticinella eubejaouaensis (muestra A6); 16) Colomiella recta (muestra A7); 17) Ticinella sp. (muestra A12); 18) Hedbergella trocoidea (muestra A35). Escala en todas las microfotografías $=200 \mu \mathrm{m}$. Escala en fotografías $1,2,4$ y $6=1 \mathrm{~cm}$. 


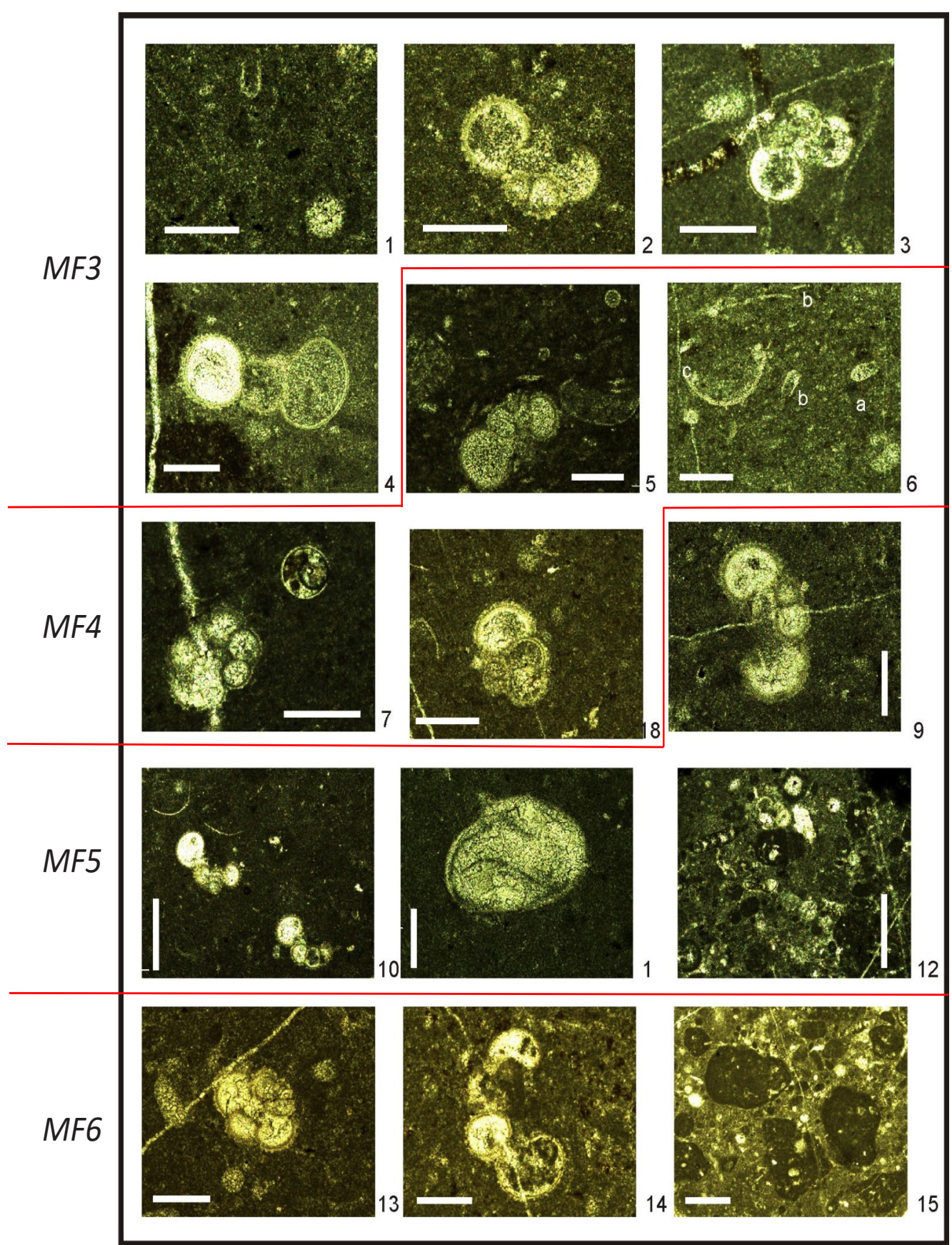

Figura 17 Fotomicrografías de las Microfacies en la Sierra Las Azules. Microfacies 3: 1) Colomiella recta y radiolario (muestra A1); 2) Ticinella bejaouaensis (muestra A5); 3) Favusella washitensis (muestra A9); 4) Hedbergella cf. delrioensis (muestra A9). Microfacies 4: 5) Hedbergella cf. delrioensis y calpionélido (muestra A18); 6) (a) Colomiella mexicana y (b) Colomiella recta, Ostrácodo (muestra A20); 7) Foraminífero planctónico, luz polarizada (muestra A20); 8) cf. Favusella sp. (muestra A29). Microfacies 5: 9) Hedbergella delrioensis (muestra A8); 10) Hedbergella trocoidea y ostrácodos (muestra A8); 11) Ostrácodo planctónico (cf. Microcalamoides), (muestra A8); 12) Anélidos, intraclastos, foraminíferos planctónicos y bentónicos (muestra A19). Microfacies 6: 13) Favusella scitula y radiolarios (muestra A21); 14) Ticinella cf. breggiensis (muestra A21); 15) Extraclastos (muestra CP22). Escala en todas las microfotografías = 200 $\mu \mathrm{m}$. 
Las microfacies de las calizas estudiadas, son similares a las descritas por López-Doncel et al. (2005) en la Sierra El Cartucho en Chihuahua, allí se describe una biomicrita (mudstone y wackestone) compuesta por bioclastos de crinoides, calciesferas, gasterópodos, foraminíferos planctónicos y bioturbación sostenidos en una matriz de micrítica. Se diferencia de aquella sección porque carece de bancos calcáreos gruesos a masivos con braquiópodos y moluscos, representados por floatstones y boundstones, en ningún estrato aquí caracterizado se observa esta composición.

En este estudio no se identificó a Orbitolina. texana u O. mexicana, los cuales son indicativos de ambientes sublitorales con alta energía, poco profunda y de plataforma interior con influencia de bioclastos (Husinec et al., 2000). En la Formación Espinazo del Diablo en Lampazos, Monreal y Longoria (2000) identificaron orbitolínidos, así como en la Caliza Loma Plata en el Banco de Lucero en Chihuahua, en cambio sí se reconoció a las especies $F$. washitensis y H. planispira, que sugieren ambientes profundos. Las microfacies identificadas en la Sierra Las Azules, así como la parte baja y media de la Sierra Banco de Lucero, pueden correlacionarse con las descritas en el estratotipo del Cerro de la Silla (Longoria, 1975), así como la parte superior de la Formación La Peña y la Caliza Tamaulipas en la Sierra del Rosario, al este de Durango. Sin embargo existen diferencias debido a que en la Caliza Tamaulipas, los crinoides son los granos esqueletales dominantes, los foraminíferos planctónicos son comunes y las calciesferas son frecuentes. Cantidades diferentes a las descritas en el presente trabajo, en donde los foraminíferos planctónicos son los organismos más abundantes,

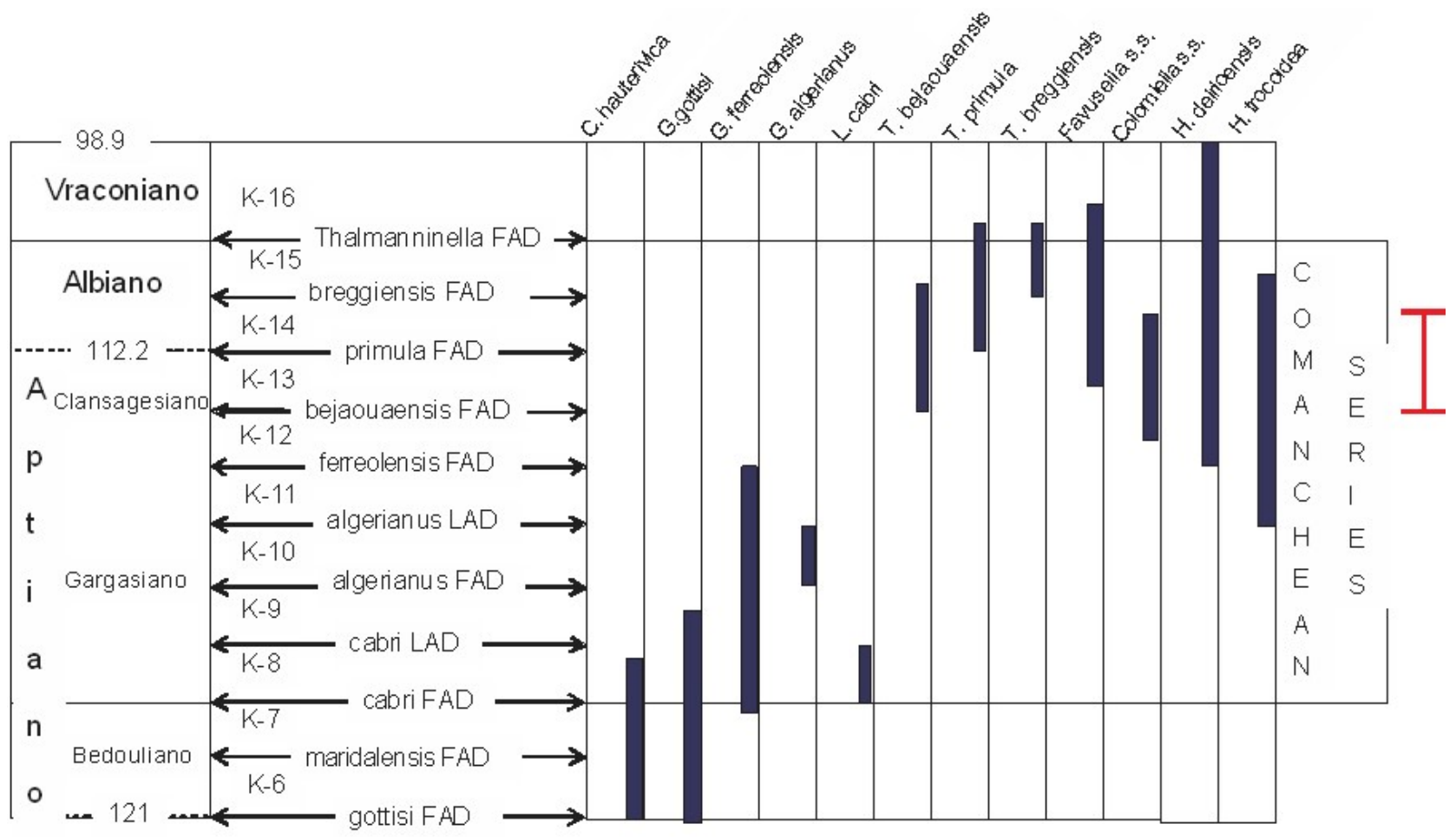

Figura 18 Posición cronoestratigráfica de las secuencias estudiadas en Lampazos, Sonora y Banco de Lucero, Chihuahua basada en la presencia de Ticinella bejaouaensis, Colomiella recta y $C$. mexicana, según el esquema bioestratigráfico de foraminíferos plantónicos de la Serie Comancheana propuesto por Longoria (1984). La barra o línea roja al margen indica el rango cronoestratigrafico de las secuencias estudiadas definido por la distribución de las especies identificadas en ambas secciones. $\mathrm{K}-6$ a $\mathrm{K}-16$ = Biozonas propuestas por Longoria (1984). FAD = First appearence datum, LAD= Last appearence datum. EI Vraconiano corresponde con una división antigua del Albiano superior. 
mientras que los crinoides solo se observan en algunos estratos. De ésta manera, la Formación La Peña se puede relacionar paleoambientalmente con la secuencia de la Sierra Las Azules, por presentar depósitos típicos de una rampa externa o pendiente, en donde existe una proliferación de foraminíferos planctónicos y una disminución de formas bentónicas.

Las secciones estudiadas coinciden bioestratigráfica y paleoambientalmente con las descritas por López-Doncel et al. (2005) para el intervalo Aptiano-Albiano inferior, donde los ambientes van de aguas profundas a moderadamente profundas, desde zonas del borde de talud (ZF4) hasta la plataforma de mar abierto (ZF2), donde existen continuos aportes de terrígenos provenientes de zonas elevadas, registrados con la presencia de lutitas y limolitas. Sin embargo, esto no ocurre en la parte alta de la Sierra Banco de Lucero, en donde el ambiente es lagunar (Figura 19), estos pueden correlacionarse con algunos estratos de la Formación Benigno del Albiano inferior (Sierra del Cartucho, Chihuahua), donde se observan faunas como miliólidos y orbitolínidos que sugieren ambientes lagunares (López-Doncel et al., 2005). Los tipos de ambientes identificados en las áreas de estudio, soportan la idea de una transgresión marina para el intervalo AptianoAlbiano en el noroeste de México, proveniente del brazo oriental del antiguo mar mexicano con sus respectivas variaciones en el nivel del mar.

Por otro lado los estilos de deformación de las áreas de estudio están relacionados entre sí. El Cinturón Tectónico de Chihuahua, se caracteriza por una serie sierras orientadas norte-noroeste, la mayoría de los cuales son estructuras antiformes. Las sierras muestran un patrón en forma de "en echelon", y las trazas de los plieegues varían de rectas a sinuosas (en forma de $\mathrm{S}$ ) curvas y/o retorcidas. En muchos casos las estructuras tienen planos axiales verticales, pero en otros exhiben planos axiales volcados y torcidos (Monreal y Longoria, 1995). Una característica diagnóstica del cinturón tectónico de Chihuahua es la vergencia opuesta de los pliegues y fallas de cabalgadura.
Similarmente, las rocas de Cretácico inferior en el área de Lampazos se encuentran fuertemente plegadas y falladas. Las estructuras más conspicuas son pliegues isoclinales y en forma de caja, y fallas de cabalgadura, ambas mayormente orientadas de norte a sur y noroeste-sureste, y con vergencias al este y oeste. Aunque las rocas se encuentran plegadas métricamente, las megaestructuras (pliegues kilométricos) son los más conspicuos. Otra característica importante de la deformación es que muchos de los pliegues están torcidos, es decir, sus vergencias cambian en direcciones opuestas de un extremo del pliegue al otro. Las fallas de cabalgadura exhiben un patrón similar, ya que también muestran vergencias en direcciones opuestas. Este estilo deformacional muestra grandes similitudes con el estilo de deformación de la faja tectónica de Chihuahua (Monreal y Longoria, 2000).

La disposición morfoestructural del cinturón tectónico de Chihuahua, así como del área de Lampazos muestra estrecha similitud con las morfologías resultantes en el modelo experimental realizado por Odonne y Vialon (1983) que simula un sistema de fallas de desplazamiento horizontal, en un basamento rígido bajo una cobertura sedimentaria, deformada durante el movimiento de dichas fallas (Monreal y Longoria, 1995, 2000). La existencia de un sistema de fallas de desplazamiento horizontal en el basamento se evidencia por la expresión morfotectónica de la cobertura sedimentaria mesozoica. Las principales evidencias de estas fallas, además de la morfoestructura regional, son las yuxtaposiciones estratigráficas presentes. Se han documentado varias yuxtaposiciones estratigráficas en el cinturón tectónico de Chihuahua, por medio de las cuales las facies de aguas someras están en proximidad cercana a facies de aguas profundas, sin evidencia de cambios laterales en tipos de facies (Monreal, 1989, 1993; Monreal et al., 1990) y las yuxtaposiciones no podrían explicarse por cambios de facies drásticas porque las rocas que representan depósitos de aguas profundas no contienen aloquímicos derivados de los depósitos de aguas poco someras o viceversa, como sería el caso si esas rocas hubie- 
ran sido originalmente depositadas cercanas unas a otras. Por lo que estas yuxtaposiciones estratigráficas se interpretan como producto de la deformación por fallas de desplazamiento horizontal en el basamento (Monreal y Longoria, 1995).

Finalmente, La secuencia del Aptiano-Albiano expuesta en Lampazos es notablemente similar a la sucesión de la cuenca de Chihuahua y representa un elemento paleogeográficos intermedio entre la cuenca de aguas someras Bisbee y la facies de agua someras y profundas de la cuenca de Chihuahua y el proto-Golfo de México. Además, el estilo de deformación de la sucesión de Lampazos es también muy similar al estilo deformacional del Cinturón Tectónico de Chihuahua. El norte de México experimentó una deformación de transpresión tectónica durante y después de la época Mesozoica (Longoria, 1985, 1987, 1988, 1993, 1994; Monreal, 1989, 1990, 1993, 1996, Monreal y Longoria, 1995).

\section{Conclusiones}

Las secciones estudiadas en la Sierra Banco de Lucero en Chihuahua y La Sierra Las Azules en Sonora, están formadas por calizas micríticas y calizas arenosas, presentando algunos intervalos con intercalaciones de lutitas. Las localidades estudiadas contienen una asociación faunística dominada por foraminíferos planctónicos, colomiélidos, foraminíferos bentónicos, radiolarios, crinoides y ostrácodos, y en menor abundancia por equinodermos, moluscos y algunos icnofósiles. Ambas secciones están compuestas por una asociación de microfósiles representada por foraminíferos de las familias Globigerinelloididae, Hedbergellidae, Favusellidae, Ticinellidae y por colomiélidos de la familia Codonellosidae, además de otros organismos identificados como ostrácodos planctónicos pertenecientes a la especie Microcalamoides diversus y a crinoides planctónicos de la especie Saccocoma sp. Petrográficamente, las calizas que componen las secciones estudiadas, se clasifican de acuerdo a su textura como wackestone en su mayoría y por su aspecto como biomicrita (salvo algunas excepciones en donde no se distinguieron fósiles), seguidos de mudstone y packstone.

De acuerdo al análisis de microfacies, los ambientes dominantes en ambas secciones son de margen de cuenca a plataforma de mar abierto, y hasta cuenca, solo en la parte alta de la localidad ubicada en Chihuahua, se reconocieron ambientes de laguna. Sin embargo, es importante mencionar que sobre la secuencia estudiada de la Formación Lampazos en la Sierra Las Azules, se tiene una secuencia de aguas someras de la Formación Espinazo del Diablo (González-León, C. M., 1988; Monreal y Longoria, 2000), pero por problemas estructurales no se pudo incluir la parte superior de la Formación Lampazos en este estudio.

Ambas localidades representan el intervalo Aptiano superior-Albiano inferior de acuerdo con la posición cronoestratigráfica sugerida por el contenido de microfósiles, sin embargo, son ligeramente diacrónicas, es decir, que posiblemente la sección en Sonora es un poco más antigua que la sección de la Sierra Banco de Lucero. El intervalo Aptiano-Albiano inferior expuesto en las dos localidades estudiadas, es representativo de una depositación durante el episodio transgresivo de inundación de la cuenca de Chihuahua. Las condiciones paleoambientales en ambas secciones, están relacionadas con las secuencias contemporáneas expuestas en la Cordillera Nuevoleonesa. Estas dos localidades se encuentran en la actualidad geográficamente muy separadas, sin embargo, presentan condiciones faunísticas y de microfacies muy similares, lo cual se interpreta como genéticamente relacionadas, es decir, ligadas a un mismo asentamiento paleogeográfico: la cuenca de Chihuahua.

Las microfacies reconocidas en las dos localidades, así como su contenido fósil, son similares a las identificadas en las secuencias del Golfo de México (en Chihuahua, Coahuila y Nuevo León). Todas estas localidades muestran asociaciones faunísticas similares, compuestas por microfósiles tales como foraminíferos bentónicos y planctónicos, colomiélidos, nanocónidos y radiolarios, lo cual se consi- 


\section{Sierra Banco de Lucero}

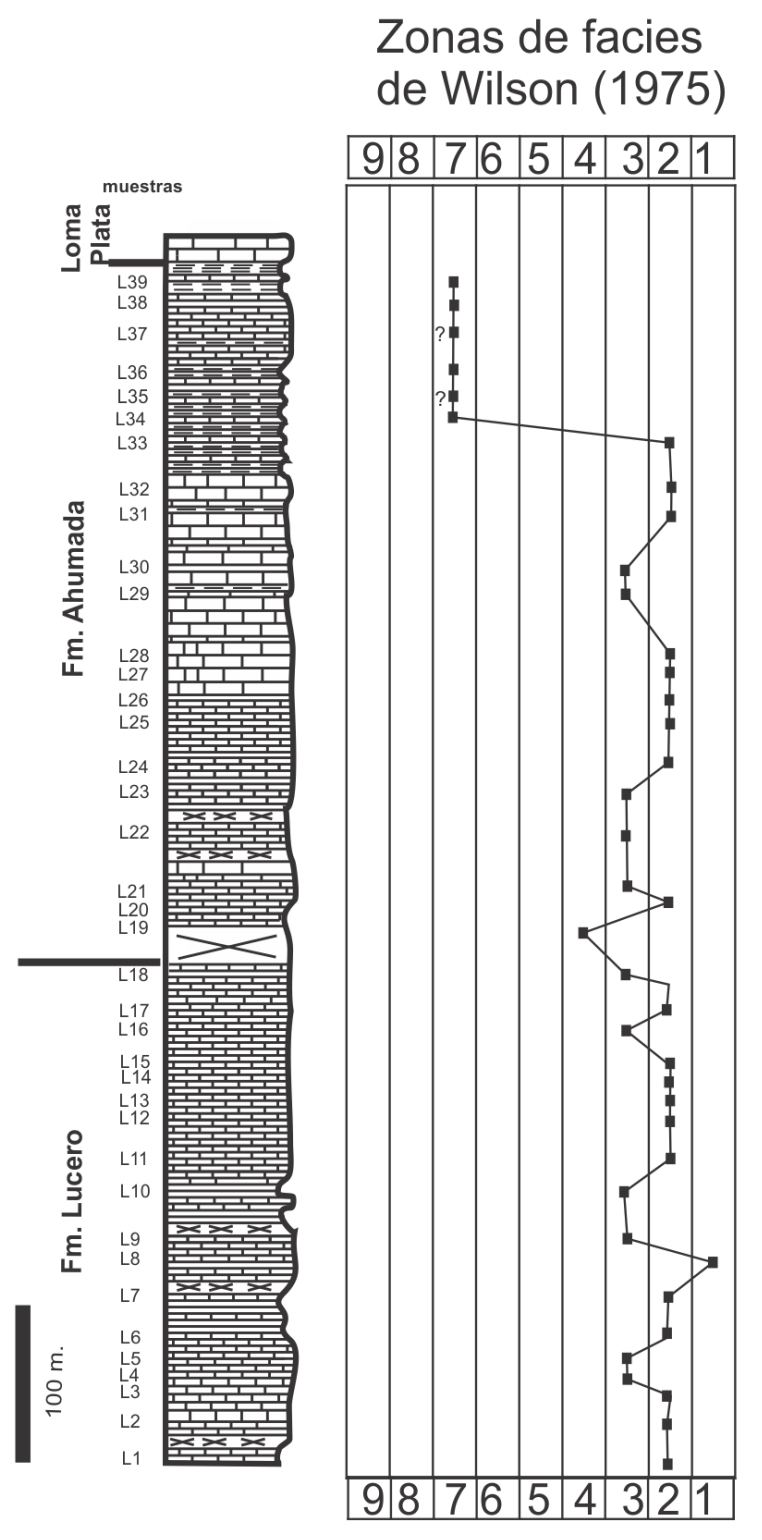

\section{Sierra Las Azules}

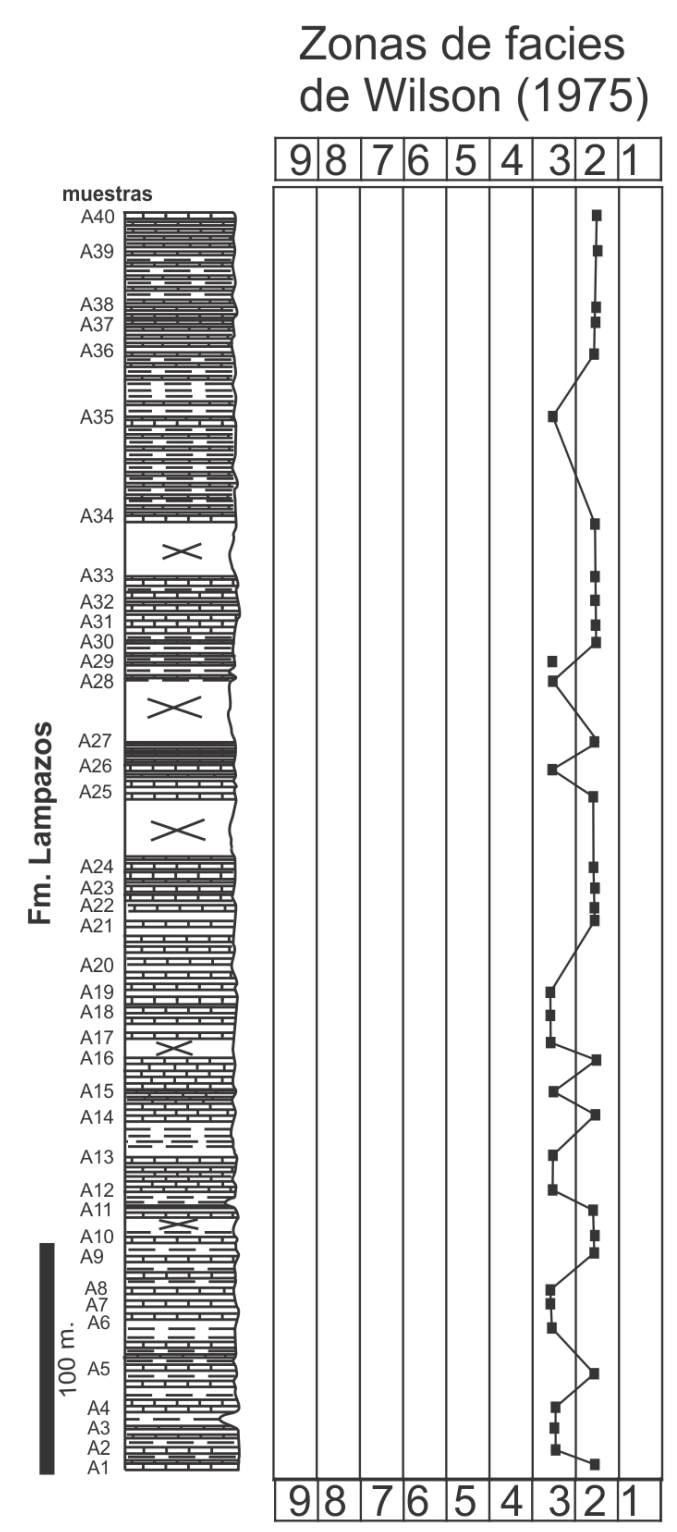

Figura 19 Evolución de sistemas deposicionales de las zonas de estudio de acuerdo al análisis de microfacies. 1= cuenca, 2=plataforma de mar abierto, $3=$ margen de cuenca (talud), $4=$ talud interior, $5=$ margen de plataforma, $6=$ bancos de arena, $7=$ laguna costera, $8=$ plataforma restringida, $9=$ plataforma evaporítica. 
dera como evidencia de la relación que guardan estas secuencias de Sonora y Chihuahua con el noreste de México.

De acuerdo con los datos obtenidos, se confirma la afinidad tanto litoestratigráfica como cronoestratigráfica de la secuencia expuesta en Lampazos con la secuencia expuesta en la Sierra Banco de Lucero del norte de Chihuahua y por consecuencia, también con las secciones contemporáneas del noreste de México (Coahuila y Nuevo León). Además, se considera que las rocas del Cretácico Inferior estudiadas en este trabajo fueron depositadas diacrónicamente con relación a la cuenca Bisbee que representa los registros más al noroeste del ancestral Golfo de México, dentro de Texas, Nuevo México y Arizona, y que se extendió al este y centro norte de Sonora (Monreal et al., 1994; Monreal, 1995).
Además, el estilo de deformación de las rocas cretácicas del área de Lampazos, Sonora es muy similar al estilo de deformación del Cinturón Tectónico de Chihuahua:

Paleogeograficamente, la sucesión de Lampazos está relacionada con la cuenca de Chihuahua y no con la cuenca de Bisbee y no tiene cabida en la distribución de facies y paleogeografía de la cuenca de Bisbee, es por lo tanto, que se presume que la transpresión tectónica ha sido el mecanismo por el cual esta sucesión ha sido movida desde la cuenca de Chihuahua y yuxtapuesta contra las sucesiones del Grupo Bisbee en Sonora (Figura 20).

La cobertura sedimentaria mesozoica de la cuenca de Chihuahua ha sido yuxtapuesta debido al plegamiento producido por una serie de fallas de desplazamiento horizontal en el basamento, responsable de las yuxtaposiciones paleogeográ-

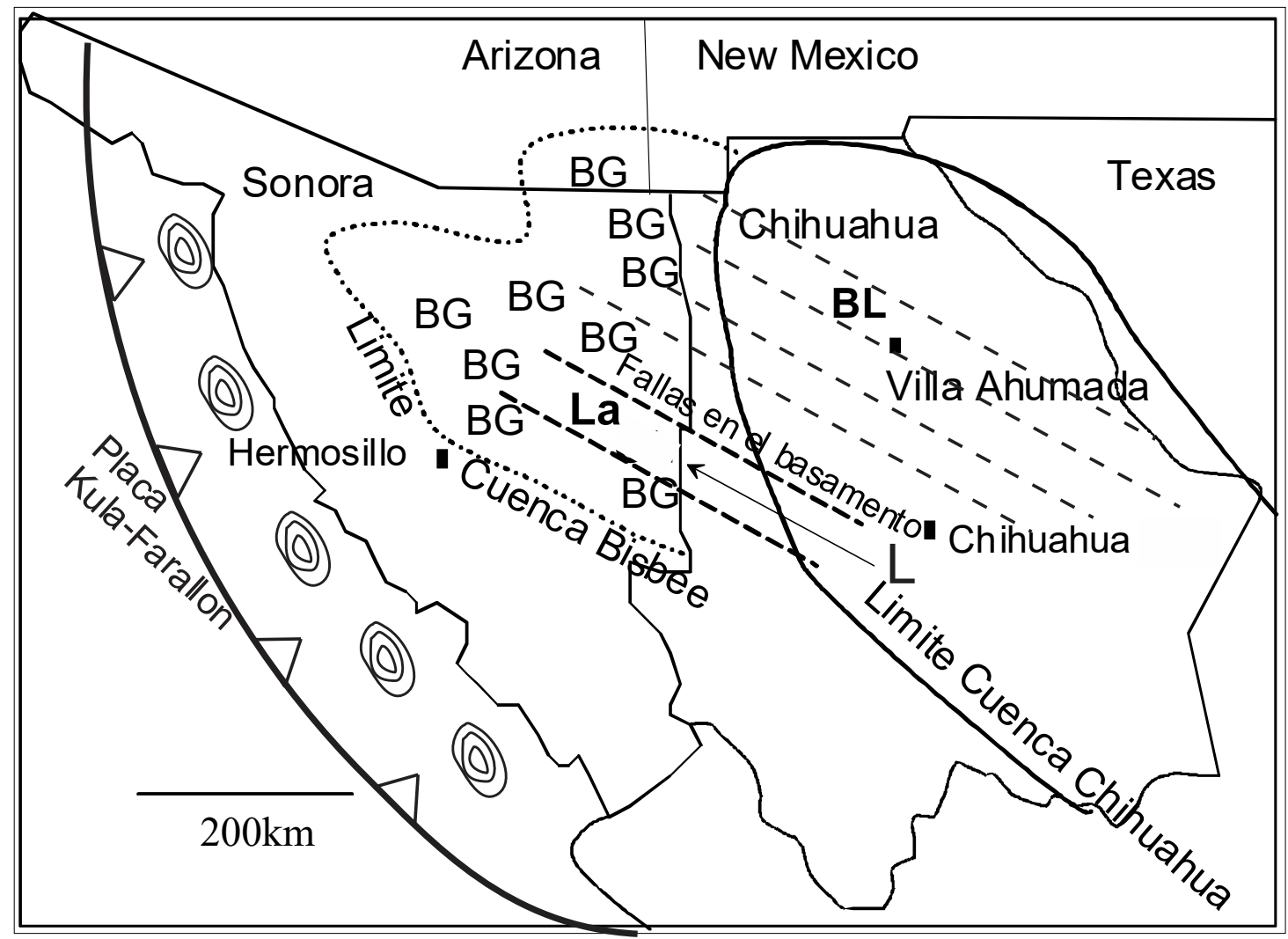

Figura 20 Relación paleogeográfica entre la sucesión estratigráfica de la Cuenca de Chihuahua, el área de Lampazos y la cuenca Bisbee. $\mathrm{BG}=$ afloramientos del Grupo Bisbee, $\mathrm{La}=$ ubicación geográfica actual del área de Lampazos, $\mathrm{L}=$ posible ubicación paleogeográfica del área de Lampazos, BL= Sierra Banco de Lucero. La flecha indica movimiento relativo de la secuencia de Lampazos desde la cuenca de Chihuahua hacia el noroeste en este central de Sonora, donde se encuentra yuxtapuesta con los afloramientos del Grupo Bisbee. 
ficas y la deformación del cinturón tectónico de Chihuahua. Estas yuxtaposiciones y patron estructural de deformación de dicho cinturón y el área de Lampazos son el resultado de un escenario de deformación de transpresión tectónica, como el propuesto por Longoria (1985) para el norte de México. Haenggi (2002) concuerda con este estilo deformacional, solamente que él considera que un flujo evaporítico incrementó el plegamiento y el cabalgamiento.

Finalmente, es importante mencionar que aunque las dos secuencias son de edad Aptiano-Albiano, por lo que son contemporáneas, la posición cronoestratigráfica exacta de las dos secuencias es casi imposible de conocer, debido al rango estratigráfico de los fósiles índice presentes. Por lo anterior es posible inferir esta relación paleogeográfica entre las dos secuencias, pero no podemos suponer que las dos secuencias se depositaron exactamente al mismo tiempo.

\section{Agradecimientos}

Agradecemos al Departamento de Geología de la Universidad de Sonora y al Centro de Investigaciones en Ciencias de la Tierra y Materiales de la Universidad Autónoma del Estado de Hidalgo, por las facilidades y apoyo brindado para la realización de este proyecto, así como al CONACYT por los recursos otorgados para la realización del posgrado del primer autor.

\section{Referencias}

Amsbury, D. L., 1957, in Keroher et al, 1966; Lexicon of Geological Names of the United States for 1936-1960. Geol. Survey. Bull. 1200, pt. 1. 4341 p. https://doi.org/10.3133/ b1200.

Adatte, T., Stinnesbeck, W., Hubberten, H., Remane, J., 1994, Correlaciones multiestratigráficas en el límite Jurásico-Cretácico en el
Noreste de México: Boletín de la Sociedad Geológica Mexicana, LI, 1 - 2 (1991 1992), 23-51. https://doi.org/10.18268/ bsgm1991v51n1a4

Ángeles-Villeda, M. E., 2004, Paleoecología y Bioestratigrafía del Contacto entre las Formaciones La Casita y Taraises en la Sierra de Minas Viejas, al Noroeste de Nuevo León, México: Nuevo León, México, UANL, tesis de Maestría, $90 \mathrm{p}$.

Araujo-Mendieta, J., 1978, Litofacies y diagénesis de la Formación Tamaulipas Inferior (Cretácico Inferior) en el subsuelo de las áreas Bejuco-La Laja, Estado de Veracruz: Boletín de la Sociedad Geológica Mexicana, 39(2), 14-24. https://doi.org/10.18268/ bsgm1978v39n2a2

Bonet, F., 1956: Zonificatión microfaunística de las Calizas Cretácicas del este de México. Boletín Asociación Mexicana de Géologos Petroleros, 8, 7-8, 389-488.

Cantú-Chapa, A., 1976, El Contacto JurásicoCretácico, la Estratigrafía del Neocomiano, el Hiato Hauteriviano Superior-Eoceno Inferior y las Amonitas del Pozo Bejuco 6 (CentroEste de México): Boletín de la Sociedad Geológica Mexicana, 37(2), 60-83. https:// doi.org/10.18268/bsgm1976v37n2a2

Canudo, J. I., 2002, Tintínidos, en Molina, E. (editor), Micropaleontología: España, Colección Textos Docentes, 265-280.

Carozzi, A. V., 1989, Carbonate rock depositional models, a microfacies approach: Englewood Cliffs, N. J., Prentice-Hall, 604 p.

Coccioni, R., Luciani, V. 2004. Planktonic foraminifera and environmental changes across the Bonarelli Event (OAE2, latest Cenomanian) in its type area: a high-resolution study from the Tethyan reference Bottaccione section (Gubbio, Central Italy). Journal of Foraminiferal Research 34, 109-129. https:// doi.org/10.2113/0340109

Córdoba, D. A., 1969, Mesozoic stratigraphy of northeastern Chihuahua, México (with Spanish abs), in Guidebook of the border 
region, New Mexico Geological Society, 20th field conference, Socorro, New Mexico, New Mexico Bur, Mines and Mineral Resources, 91-96.

Dunham, R.J., 1962, Classification of carbonate rocks according to depositional texture, in Ham, W.E. (ed.), Classification of carbonate rocks: American Association of Petroleum Geologists Memoir, 1, 108-121.

Flügel, E., 1982, Microfacies Analysis of Limestones, Berlin, Heidelberg, Springer-Verlag, 633 p. https://doi.org/10.1007/978-3-642-68423-4

Flügel, E., 2004, Microfacies of Carbonate Rocks, Analysis, Interpretation and Application: Germany, Springer-Verlag, 976 p.

Folk, R. L., 1962, Spectral subdivision of limestone types. In W.E. Ham (Ed.), Classification of Carbonate Rocks - A Symposium. American Association of Petroleum Geologists memoir 1, 62-84 .

Gamper, M, A., 1977, Estratigrafia y Microfacies Cretácicas del Anticlinorio Huizachal-Peregrina (Sierra Madre Oriental): Boletín de la Sociedad Geológica Mexicana, 38(2), 1-17. https://doi. org/10.18268/bsgm1977v38n2al

González-Arreola, C., Carrillo-Martínez, M., 1986, Amonitas del Jurásico Superior (Titoniano Superior) y del Cretácico Inferior (HauterivianoBarremiano) del área de San Joaquín-Vizarrón, estado de Querétaro: Revista del Instituto de Geología 6(2), 171-177.

González-León, G. M., 1988, Estratigrafia y geología estructural de las rocas sedimentarias Cretácicas del área de Lampazos, Sonora: Revista del Instituto de Geología 7(2), 148-162.

González-León, C. M., Scott, R. W., Löser, H., Lawton T. F., Robert E., Valencia, V. A., 2008, Upper Aptian-Lower Albian Mural Formation: Stratigraphy, biostratigraphy and depositional cycles on the Sonoran shelf, northern México, Cretaceous Research, 29(2), 249-266. https:// doi.org/10.1016/j.cretres.2007.06.001

Ghosh, A.K., Sarkar, S., 2013, Facies analysis and paleoenvironmental interpretation of Piacenzian carbonate deposits from the Guitar
Formation of Car Nicobar Island, India. Geoscience Frontiers 4(6), 755-764. https://doi. org/10.1016/j.gsf.2013.01.010

GSA (Geological Society of America, The), 1996, The Rock Color Chart Committee, Octava impres $\neg$ sion, The Geological Society of America, Colorado U.S.A.

Guerrero, J. C., 1969, Stratigraphy of Sierra Banco de Lucero, state of Chihuahua, en Córdoba, D.A., Wengerd, S.A. and Shomaker, J. (eds.), The Border Region: New Mexico Geological Society 20th. Field Conference Guidebook. 171-172.

Haenggi, W. T., 2002, Tectonic history of the Chihuahua trough, Mexico and adjacent USA, Part II: Mesozoic and Cenozoic: Boletín de la Sociedad Geológica Mexicana , 54, 38-94. https://doi.org/10.18268/bsgm2002v55nla4

Herrera, S., Bartolini, G., 1983, Geología del área de Lampazos Sonora:, Universidad de Sonora, Hermosillo, Sonora, México, Tesis profesional $120 \mathrm{p}$.

Husinec, A., Velic, I., Fucek, L., Vlahovic, I., Maticec, D., Ostric, N., Korbar, T., 2000, Mid Cretaceous orbitolinid (Foraminiferida) record from the islands of Cres and Losinj (Croatia) and its regional stratigraphic correlation, Cretaceous Research, 21, 155-171. https://doi.org/10.1006/ cres. 2000.0203

Longoria,J.F., 1968, Estudio en sección delgada de algunas especies del genero Globotruncana Cushman del Santoniano-Maestrichtiano de México. Asociación Mexicana de Geólogos Petroleros, Boletín. 20, 41-117.

Longoria, J. F., 1973, On the stratigraphic distribution of the Tintinnid genus Colomiella, Boletín de la Sociedad Geológica Mexicana, 34(1 y 2), 97-99. https://doi. org/10.18268/bsgm 1973v34nla8

Longoria, J. F., 1974, Stratigraphic, morphologic and taxonomic studies of Aptian planktonic foraminífera. Revista Española de Micropaleontología, Número extraordinario, $107 \mathrm{p}$. 
Longoria, J.K., 1975, Estratigrafía de la serie Comancheana del noreste de México, Boletín de la Sociedad Geológica Mexicana, 36(1), 31-59. https://doi.org/10.18268/ bsgm 1975v36n la2

Longoria, J. F., 1977, Bioestratigrafía del Cretácico Inferior basada en microfósiles planctónicos: Boletín de la Sociedad Geológica Mexicana, 38(1), 2-17. https://doi.org/10.18268/ bsgm 1977v38nlal

Longoria, J. F., 1984, Cretaceous biochronology from the Gulf of Mexico region based on planktonic microfossils: Micropaleontology, 30 (3), 225-242. https://doi. org/10.2307/1485687

Longoria, J. F., 1985, Tectonic transpression in the Sierra Madre Oriental, northeastern Mexico: an alternative model: Geology, 13(7), 453-456. https://doi.org/10.1130/0091$7613(1985) 13<453$ :ttits m>2.0. co;2

Longoria, J. F., 1987, Paleogeographic development of Mexico during the Cretaceous, in J. M. Barbarin, H. J. Gursky, and P. Meiburg, (eds.), Simposio Internacional: El Cretácico de México y America Central, Resúmenes, Actas Facultad de Ciencias de la Tierra, Universidad Autónoma de Nuevo León, Linares Nuevo León, 2, 177-190.

Longoria, J. F., 1988, Tectonic evolution of the western margin of Mexico: Geodynamics Research Institute Texas A\&M University Geodynamics Symposium, 34-37.

Longoria, J. F., 1993, La terrenoestratigrafia: un ensayo de metodología para el análisis de terrenos con un ejemplo en México: Boletín de la Asociación Mexicana de Geólogos Petroleros, 43, 30-48.

Longoria, J. F., 1994, Recognition and characteristics of a strike-slip fault system in Mexico and its Mesozoic transpressional regime: implications in plate tectonics and paleogeographic reconstruc-tion: Boletín del Departamento de Geología de la Universidad de Sonora, 11, 77-104.
Longoria J.F., Gamper, M, 2002 The small globigerinas fauna: a clue in the evolution of planktonic foraminifera across the $\mathrm{K} / \mathrm{T}$ boundary. In: Agustin Ayala-Castanares: universitario impulsor de la investigación científica (L.A. Soto, Ed.) (Inst. de Ciencias del Mar y Limnología, Universidad Nacional Autónoma de México, 282-302.

Longoria, J. F., Monreal, R., 1991, Lithostratigraphy, microfacies, and depositional environments of the Mesozoic of Sierra La Nieva, Coahuila, Northeast Mexico, Revista de la Sociedad Geológica de España, 4(1-2), 7-31.

Longoria, J. F., Monreal, R., 2009, The use of planktonic microfossils to resolve chronos-tratigraphic, tectonic, and paleogeographic uncertainties in the Lower Cretaceous of eastern Sonora, NW Mexico, SEPM (Society for Sedimentary Geology), Geologic Problem Solving with Microfossils, 269-285. https://doi. org/10.2110/sepmsp.093.269

López-Doncel, R., Labarthe-Hernández, G., y Mata-Segura, J. L., 2005, Estudio sedimentológico de la Sierra Las Lilas (Paleozoico) y Sierra El Cartucho (Mesozoico) en la porción noroccidental del estado de Chihuahua, México (Distrito minero de Bismark): Revista Mexicana de Ciencias Geológicas, 22(3), 298-314.

MacKenzie, W. S., Adams, A. E., 1997, Atlas en color de rocas y minerales en lámina delgada. Masson, S.A. Barcelona, 216 p.

Monreal, R., 1989, Regional stratigraphic studies of the Lower Cretaceous in northern México and the United States. The University of the Texas at Dallas. Ph.D. Thesis, $371 \mathrm{p}$.

Monreal, R., 1990, Paleogeografía y tectónica del Cretácico Inferior del centro-norte de México: Vinculación, 2, 13-29.

Monreal, R., 1993, Paleogeografía y tectónica de la cuenca de Chihuahua durante el Cretácico Inferior: Boletín del 
Departamento de Geología, Universidad de Sonora, 10, 1-20.

Monreal, R., Longoria, J.F., 1995, Transpressional deformation pattern related to basement faults in the Mesozoic of northeastern Chihuahua: Boletín del Departamento de Geología de la Universidad de Sonora, 12(2), 17-34.

Monreal, R., 1996, Cretaceous stratigraphy and structure of Sierra Grande, northeastern Chihuahua, in J. Roldan, C. Jacques, and C. González, (eds.), Studies of the Mesozoic of Sonora and adjacent areas: Geological Society of America Special Paper 301, 167-178. https://doi. org/10.1130/0-8137-2301-9.167

Monreal, R., 2009, El Cretácico del este de Sonora y su relación con el Cretácico de Chihuahua, XXVIII Convención Minera Internacional, AIMMGM AG, Veracruz., del 28 al 31 de octubre, 7-14.

Monreal, R., Longoria, J.F., 1999, A revision of the Upper Jurassic and Lower Cretaceous stratigraphic nomenclature for the Chihuahua trough, north-central Mexico: Implications for lithocorrelations. In: Mesozoic Sedimentary and Tectonic History of North-Central Mexico, G. Bartolini, J. Wilson, and T. Lawton, eds., Geological Society of America Special Paper 340, 69-92. https://doi. org/10.1130/0-8137-2340-x.69

Monreal, R., Longoria, J.F., 2000, Stratigraphy and structure of the Lower Cretaceous of Lampazos, Sonora, (northwest Mexico) and its relationship to the Gulf Coast succession: American Association of Petroleum Geologists Bulletin, 84 (11), 1811-1831.

Monreal, R., Valenzuela, M., González-León, C., 1994, A revision of the stratigraphic nomenclature for the Cretaceous of northern Sonora, and some paleogeographic implications, Boletín del departamento de Geología, Universidad de Sonora. 11(1), 171-190.
Odonne, F. Vialon, P., 1983, Analogue models of folds above a wrench fault: Tectonophysics, 99, 31-46.

Pettijohn, F.J. 1975. Sedimentary Rocks. 3rd ed. Harper \& Row Publ. New York. 628 p.Rodríguez, T. R., Guerrero, G. J., 1969, Hoja Villa Ahumada, 13R-a(9) con Resumen de la geología de la Hoja Villa Ahumada, Estado de Chihuahua: Universidad Nacional Autonoma de México, Instituto de Geología, Carta Geológica de México, serie $1: 100,000$.

Scholle, P. A., Ulmer-Scholle, D. S., 2003, A color guide to the petrography of carbonate rocks: Grains, textures, porosity, diagenesis, American Association of Petroleum Geologists Tulsa, Oklahoma, U.S.A. 459 p.

Scott, R. W., Gonzalez-León, C. M., 1991, Paleontology and biostratigraphy of Cretaceous rocks, Lampazos area, Sonora, in E. Perez-Segura and C. Jacques-Ayala, (eds.), Studies of Sonoran Geology: Geological Society of America, Special Paper 254, 51-67.

Solano-Rico, B., 1970, Geología y yacimientos minerales del distrito de Lampazos, Sonora: Universidad Nacional Autónoma de México, Facultad de Ingeniería, México, Unpublished B.S. Thesis, 103 p.

Taylor, A. M., Goldring, R. 1993, Description and analysis of bioturbation and ichnofabric. Journal of the Geological Society, 150, 141-148.

Trejo, H. M., 1980, Distribución estratigráfica de los tintínidos mesozoicos mexicanos, Revista del Instituto Mexicano del Petróleo, 12(4), 4-13.

Villaseñor-Martínez, A. B., González-Arreola, C., 1988, Fauna de Amonitas y presencia de Lamellaptychus murocostatus del Jurásico Superior de la Sierra de Palotes, Durango: UNAM. Instituto de Geología, 7(1), 71-77.

Wilson, J. L., 1975, Carbonate facies in Geologie History: Berlin Springer, 471 p. 